\title{
29. 2145
}

\section{DOE/JPL/954786-5}

DEVELOPMENT OF PULSED PROCESSES FOR THE MANUFACTURE OF SOLAR CELLS

Quarterly Progress Report No. 3, April-July 1978

July 1978

Work Performed Under Contract No. NAS-7-100-954786

Spire Corporation

\section{MASTER}

Bedford, Massachusetts

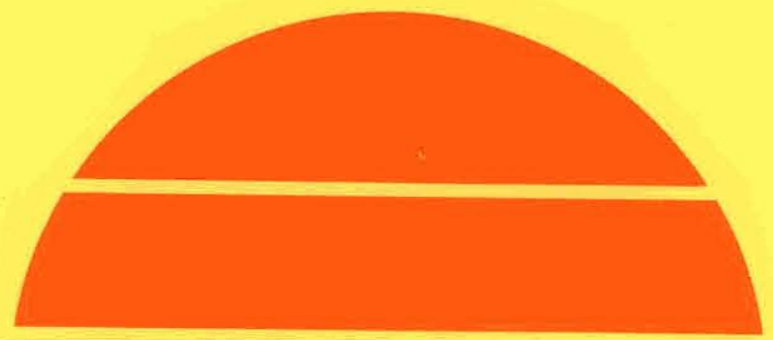

\section{U.S. Department of Energy}

\section{Solar Energy}




\section{DISCLAIMER}

This report was prepared as an account of work sponsored by an agency of the United States Government. Neither the United States Government nor any agency Thereof, nor any of their employees, makes any warranty, express or implied, or assumes any legal liability or responsibility for the accuracy, completeness, or usefulness of any information, apparatus, product, or process disclosed, or represents that its use would not infringe privately owned rights. Reference herein to any specific commercial product, process, or service by trade name, trademark, manufacturer, or otherwise does not necessarily constitute or imply its endorsement, recommendation, or favoring by the United States Government or any agency thereof. The views and opinions of authors expressed herein do not necessarily state or reflect those of the United States Government or any agency thereof. 


\section{DISCLAIMER}

Portions of this document may be illegible in electronic image products. Images are produced from the best available original document. 


\section{NOTICE}

This report was prepared as an account of work sponsored by the United States Government. Neither the United States nor the United States Department of Energy, nor any of their employees, nor any of their contractors, subcontractors, or their employees, makes any warranty, express or implied, or assumes any legal liability or responsibility for the accuracy, completeness or usefulness of any information, apparatus, product or process disclosed, or represents that its use would not infringe privately owned rights.

This report has been printed directly from copy supplied by the originating organization. Although the copy supplied may not in part or whole meet the standards for acceptable reproducible copy, it has been used for reproduction to expedite distribution and availability of the information being reported.

Available from the National Technical Information Service, U. S. Department of Commerce, Springfield, Virginia 22161.

Price: Paper Copy $\$ 5.25$

Microfiche $\$ 3.00$ 
DOE/JPL/954786-5

Distribution Category UC-63b

\section{DEVELOPMENT OF PULSED PROCESSES}

FOR THE MANUFACTURE OF SOLAR CELLS

Contract Number 954786

For the Period of

April - July 1978

This report was propared sponsored by the United States Covern accunt of work

United States nor the United States Departher the

Energy, nor any of their employecs, Der any of their

contractors, subcontractors, or their employs of their

any warranty, express or implied or apoyees, makes liability or responsibility for the or assumes any legal or usefulness of any information, appora, completenes process disclosed, or represents thas iss us, product or infringe privately owned rights. hat its use would no

Prepared for:

JET PROPULSION LABORATORY

California Institute of Technology

Pasadena, CA 91103

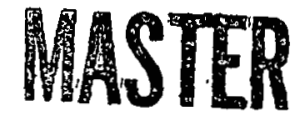

Prepared by: $\frac{\int a \ln }{\text { principal Investigator }}$

Approved by: $\frac{\text { Aft }}{\text { Program Manager }}$

SPIRE CORPORATION

Patriots Park

Bedford, MA 01730 


\begin{abstract}
This report describes third quarter results under a program to develop ion implantation and specialized, associated processes necessary to achieve automated production of silicon solar cells. The report describes ion implantation facility development for solar cell production and presents a design for an automated production implanter. It also discusses solar cell development efforts using combined ion implantation and pulsed energy techniques. Cell performance comparisons have also been made in which junctions and back surface fields were prepared by diffusion and ion implantation. A model is presented to explain the mechanism of ion implantation damage annealing using pulsed energy sources. Functional requirements have been determined for a pulsed electron beam processor for annealing ion implantation damage at a rate compatible with a 100 milliampere ion implanter. These rates result in a throughput of 100 megawatts of solar cell product per year.
\end{abstract}


TABLE OF CONTENTS

\begin{tabular}{|c|c|c|}
\hline Section & & $\underline{\text { Page }}$ \\
\hline I & INTRODUCTION & 1 \\
\hline \multirow[t]{4}{*}{ II } & $\begin{array}{l}\text { ION IMPLANTATION FACILITIES FOR SOLAR } \\
\text { CELL PRODUCTION }\end{array}$ & 3 \\
\hline & 2.1 Dedicated Process Solar Cell Implanter & 3 \\
\hline & $\begin{array}{l}\text { 2.2 Design of an Automated Production Ion } \\
\text { Implanter }\end{array}$ & 4 \\
\hline & $\begin{array}{l}\text { Economic Characterization of Ion } \\
\text { Implantation }\end{array}$ & 21 \\
\hline \multirow[t]{5}{*}{ III } & SOLAR CELL PROCESS DEVELOPMENT & 25 \\
\hline & $3.1 \quad$ Objectives & 25 \\
\hline & $\begin{array}{l}\text { Development of Processes for Ion } \\
\text { Implanted, Pulse Annealed Solar Cells }\end{array}$ & 25 \\
\hline & Cast Polycrystalline Silicon Solar Cells & 26 \\
\hline & $\begin{array}{l}\text { Solar Cell Manufacturing Process } \\
\text { Comparisons }\end{array}$ & 28 \\
\hline \multirow[t]{4}{*}{ IV } & PULSED ENERGY PROCESSING STUDIES & 43 \\
\hline & 4.1 Objectives & 43 \\
\hline & $\begin{array}{l}\text { Development of a Model of Pulsed } \\
\text { Energy Processes }\end{array}$ & 43 \\
\hline & $\begin{array}{l}\text { Design of an Automated Production Pulse } \\
\text { Processor }\end{array}$ & 51 \\
\hline V & SUMMARY & 61 \\
\hline VI & NEW TECHNOLOGY & 63 \\
\hline & & 65 \\
\hline
\end{tabular}


Sheet Resistance Contour Map for Ion Beam and Neutral Beam of High Current Implanter After Annealing

Sheet Resistance Contour Map for Neutral Beam Component Only of High Current Implanter After Annealing

Vacuum Control System Block Diagram

Solar Cell Ion Implantation System Block Diagram

Ion Source and Source Power Supplies Diagram

Vacuum System Block Diagram

Carrier for $100 . \mathrm{MM}$ Diameter Wafer

10 I-V Characteristics for Cells Processed Using Pulsed Annealing of Both Phosphorus Junction and Boron BSF Implanted Layers

11 I-V Characteristics for Polycrystalline Cells with Implanted $\mathrm{n}^{+}$and $\mathrm{p}^{+}$Structure

Distribution of $V_{O C}$ for Diffused Junction and

13 Distribution of $\mathrm{I}_{\mathrm{Sc}}$ for Diffused Junction and Alloyed BSF Test Cells

14 Distribution of $\mathrm{I}_{450}$ for Diffused Junction and Alloyed Junctions and BSF Cells

15. Distribution of $\mathrm{I}_{\mathrm{SC}}$ for Implanted and Furnace Annealed Junctions and BSF Test Cells

Distribution of $\mathrm{V}_{\mathrm{oc}}$ for Implanted and

Furnace Annealed Junctions and BSF Test Cells

Distribution of $\mathrm{I}_{450}$ for Implanted and

Furnace Annealed Junction and BSF Test Cells

Distribution of $\mathrm{I}_{\mathrm{SC}}$ for Implanted/Furnace

Annealed BSF and Implanted/Pulse Annealed

Junction Test Cells 
$\underline{\text { Number }}$

19 Distribution of $\mathrm{V}_{\text {oc }}$ Implanted/Furnace Annealed BSF and Implanted/Pulse Annealed Junction Test Cells

20 Distribution of $\mathrm{I}_{450}$ for Implanted/Furnace Annealed BSF and Implanted/Pulse Annealed Junction Test Cells

21 I-V Characteristics for Cells Processed Using Pulsed Nd:Yag Laser Annealed Implanted Junctions . and Alloyed $\mathrm{p}^{+}$layers

22 Energy Deposition vs. Depth Profile in Silicon for Pulsed Electron Beam

23 Variation of Thermal Conductivity with Temperature for Amorphous and Crystalline Silicon

24 Front Surface Temperature as a Function of Time following Deposition of Pulsed Electron Beam

Calculated Temperature Profile During Pulsed

Electron Beam Annealing from VXTEMP Output

Predicted Temperature Profile After Pulsed Electron Beam Energy Deposition

Design Concept for a Combined Implantation

Pulse Processor with a Throughput of $500 \mathrm{~cm}^{2} / \mathrm{sec}$ 


\section{LIST OF TABLES}

Number

$\underline{\text { Page }}$

I

Summary of SAMICS Analysis for Ion Implanted Junctions

22

II . Summary of Second Performance Comparison of Cell Manufacturing Techniques

III Summary of Measured Fracture Thresholds for Pulsed Electron Beam Heating as a Function of Silicon Crystallographic Orientation

IV Functional Requirements for Prototype

Pulsed Electron Beam Processor 


\section{SECTION 1}

\section{INTRODUCTION}

This is the third quarterly report under Contract Number 954786, "Development of Processes for the Manufacture of Solar Cells", being performed under the Automated Array Assembly Task of the LSA project. Development over the long term is directed towards an extremely abbreviated production scheme for the manufacture of solar cells, which precludes the use of thermal operations and wet chemistry. Immediate emphasis is upon the major element of the production concept: ion implantation. Ion implantation equipment, ion implantation processes, and advanced procedures for annealing of ion implantation damage are being addressed.

Under a previous contract ${ }^{(1)}$, it was demonstrated that silicon solar cells can be fabricated very rapidly without furnace treatments, wet chemistry or gas atmosphere operations if ion implantation is employed in conjunction with pulsed energy techniques. Other studies ${ }^{(2,3,4)}$ have shown that ion implantation will be economically advantageous for automated production if practical, large throughput ion implanters can be constructed. Further economic advantages are realized if equivalent throughput pulse processors can be constructed for annealing the ion implantation damage.

Important questions associated with ion implantation and implanted solar cells are being addressed. Conventional ion implantation facilities have been technically inadequate for simple preparation of high efficiency cells, and even the larger machines have had very low solar cell throughput capacities. Performance optimization of ion implanted solar cells had received little attention during recent years and implanted cell efficiencies have fallen behind those associated with the best diffused junction cell technology until recently. Emphasis of this program involves resolution of questions regarding hardware and economics of ion implantation for automated production. It also involves introduction of high efficiency characteristics by implantation, such as back surface fields and shallow junctions to the solar cell structure. To support this effort, the first high 
throughput dedicated solar cell implanter yet produced was installed and employed to fabricate solar cells with AM1 efficiencies greater than $16 \%$. This 3 millampere ion implanter, which has been operational for the last six months, has a throughput of $1 \mathrm{MW}$ of solar cell product per year.

A 100 millampere, automated production ion implantation system has been designed to process $100 \mathrm{MW}$ of solar cells per year. Although ion implantation is expected to become the basis of several candidate approaches to automated solar cell production, the most promising concept involves the application of directed energy pulses of sub-microsecond duration to replace the thermal operations of cell fabrication. The most important of these operations is annealing of ion implantation damage in the crystal lattice. Pulse annealing, which has been shown to produce the necessary recrystallization effect, is being studied under this program to establish the optimum process parameters and to identify the physical mechanisms involved. In summary, the major elements of the program include:

- Installation and operation of a dedicated solar cell ion implanter,

- Conceptual design of a next generation solar cell implanter for automated production,

- Development of processes for high efficiency ion implanted cell fabrication,

- Development and analysis of pulsed energy solar cell processing techniques. 


\section{SECTION II \\ ION IMPLANTATION FACILITIES FOR \\ SOLAR CELL PRODUCTION}

\subsection{DEDICATED SOLAR CELL IMPLANTER}

A dedicated solar cell implanter has been designed and fabricated in conjunction with Varian/Extrion Division. The design has adapted state-of-the-art implanter equipment technology to solar cell production requirements. An end station wafer processor was selected which utilizes a high percentage of available beam currents to achieve a throughput of up to 300 wafers per hour for junction implants. The machine operates over a low ion energy range from 5 to $50 \mathrm{keV}$ which is of interest for shallow junction high efficiency solar cell processing. Other unique features of this implanter include:

- Rotation of the wafer during implantation at one rotation per second in order to produce uniform doping of texturized surfaces,

- Elimination of fixture shadowing due to absence of holding devices,

- Continuous wafer processing rather than batch loading,

- Magnetic field oscillation of the ion beam to provide necessary implant dose uniformity.

The requirements for dose uniformity for both the junction and back surface field implant have been determined. The implanter uses an external oscillating magnetic field to scan the ion beam over the surface of the wafer. Dose uniformity is a function of ion beam energy, ion species, degree of overscan and scan frequencies. However, in this system circumferential uniformity is assured under all scanning conditions because of the rotation of the wafer during implant. Efforts during the third quarter have determined the implanter electromagnetic scanner parameters necessary to achieve doping uniformity better than $\pm 10 \%$ across the wafer surface. 
The neutral beam component for the dedicated process solar cell implanter has also been characterized. To quantatively determine the magnitude and distribution of the neutral beam, two types of wafers were processed. One wafer lot was implanted with $2 \times 10^{15},{ }^{31} \mathrm{P}^{+} \mathrm{cm}^{-2}$ at $35 \mathrm{keV}$ using the standard beam scanning conditions. This energy was chosen because it is the energy at which all ions pass through the analyzer magnet. A second lot was then implanted with only the neutral phosphorus beam by deflecting all of ${ }^{31} \mathrm{P}^{+}$away from the target wafer with a large d.c. magnetic field: Since the implanter dose intergrator cannot monitor the neutral beam implants, because there is no charge collection, the wafer was exposed for a time equal to the $35 \mathrm{keV},{ }^{31} \mathrm{P}^{+}$implant. Results are contained in Figures 1 and 2. Both sheet resistance contour maps show circumferential uniformity characteristic of rotation of the wafer during the implant. The neutral beam uniler the present configuration accounts for an additional $4.7 \%$ of ${ }^{31} \mathrm{P}^{0}$ dose over the entire wafer. Present facility modifications to reduce the magnitude of the neutral beam include a new graphite aperture at the ion source exit. This aperture has been designed to lower the pressure in the analyzer. magnet vacuum chamber from $5 \times 10^{-5}$ to $5 \times 10^{-6}$ torr. Decreasing the vacuum pressure has the effect of reducing the probability of an ion-gas molecule collision and hence reduces the neutral beam component.

During the remainder of the program, this implanter will be used for solar cell development efforts including solar cell process comparisons and development of new manufacturing processes for polycrystalline silicon cells involving ion implantation with both furnace annealing and pulsed energy annealing.

\subsection{DESIGN OF AN AUTOMATED PRODUCTION ION IMPLANTER}

The implanter described in Section 2.1 and installed at Spire can serve the immediate needs for implanted solar cell process development. But if implantation is to become practical for use in automated production to meet the mid-1980 LSA objectives, dedicated machines with higher beam currents and faster throughputs must be developed. The basic design specification for such a solar cell production 


\section{SHEET RESISTANCE MAP}

\section{Signetics Corp. 15 May 1978 19:11}

U3357 Spires Phos. Implant Wafer \#1184-1 $35 \mathrm{keV} 2 \times 10^{15} 31_{\mathrm{P}}{ }^{+} \mathrm{cm}^{-2}$

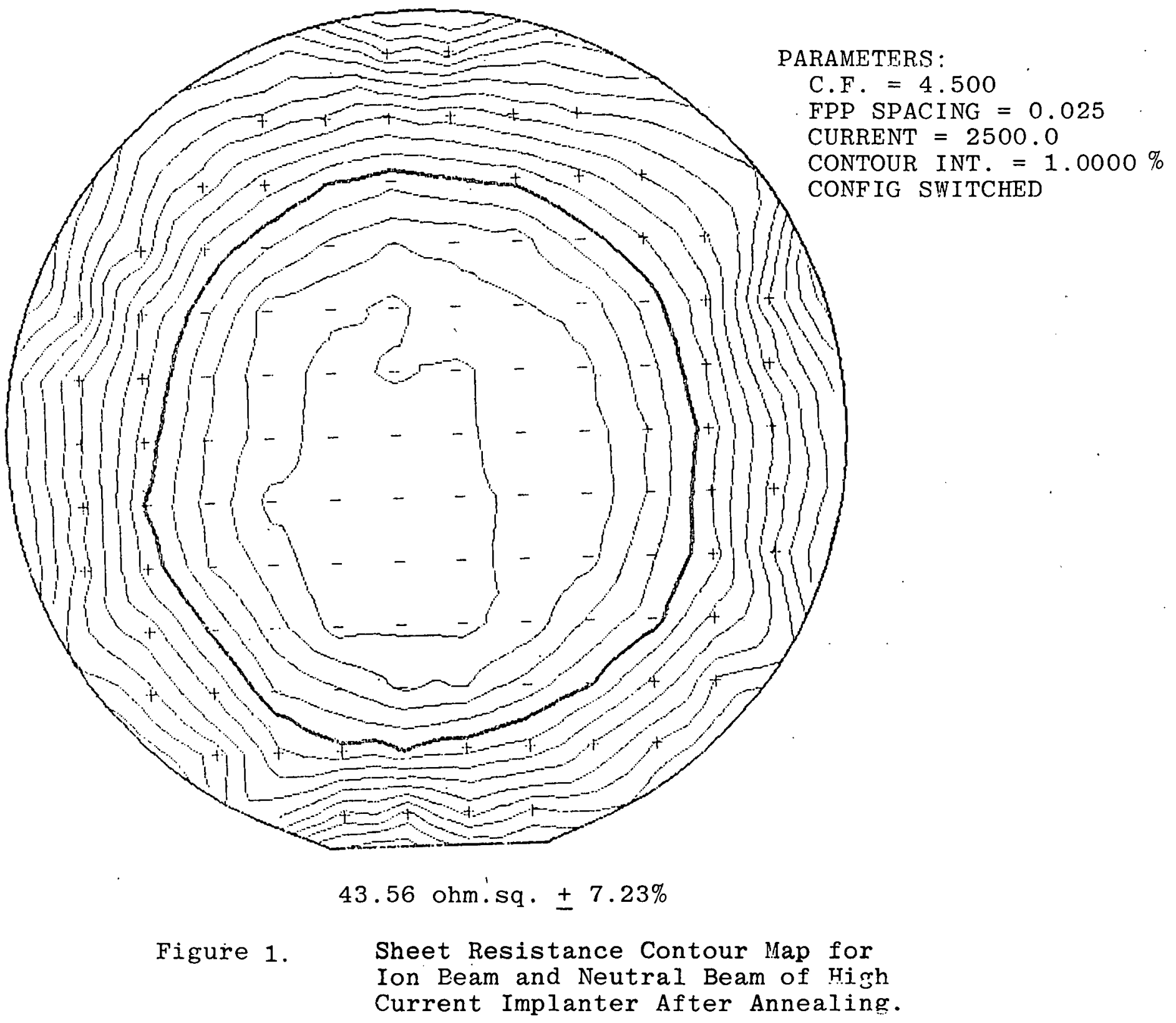




\section{SHEET RESISTANCE MAP}

Signetics Corp. 15 May 1978 19:56

U3358 Spires Phos. Implant Wafer \#1184-2 $35 \mathrm{keV}$

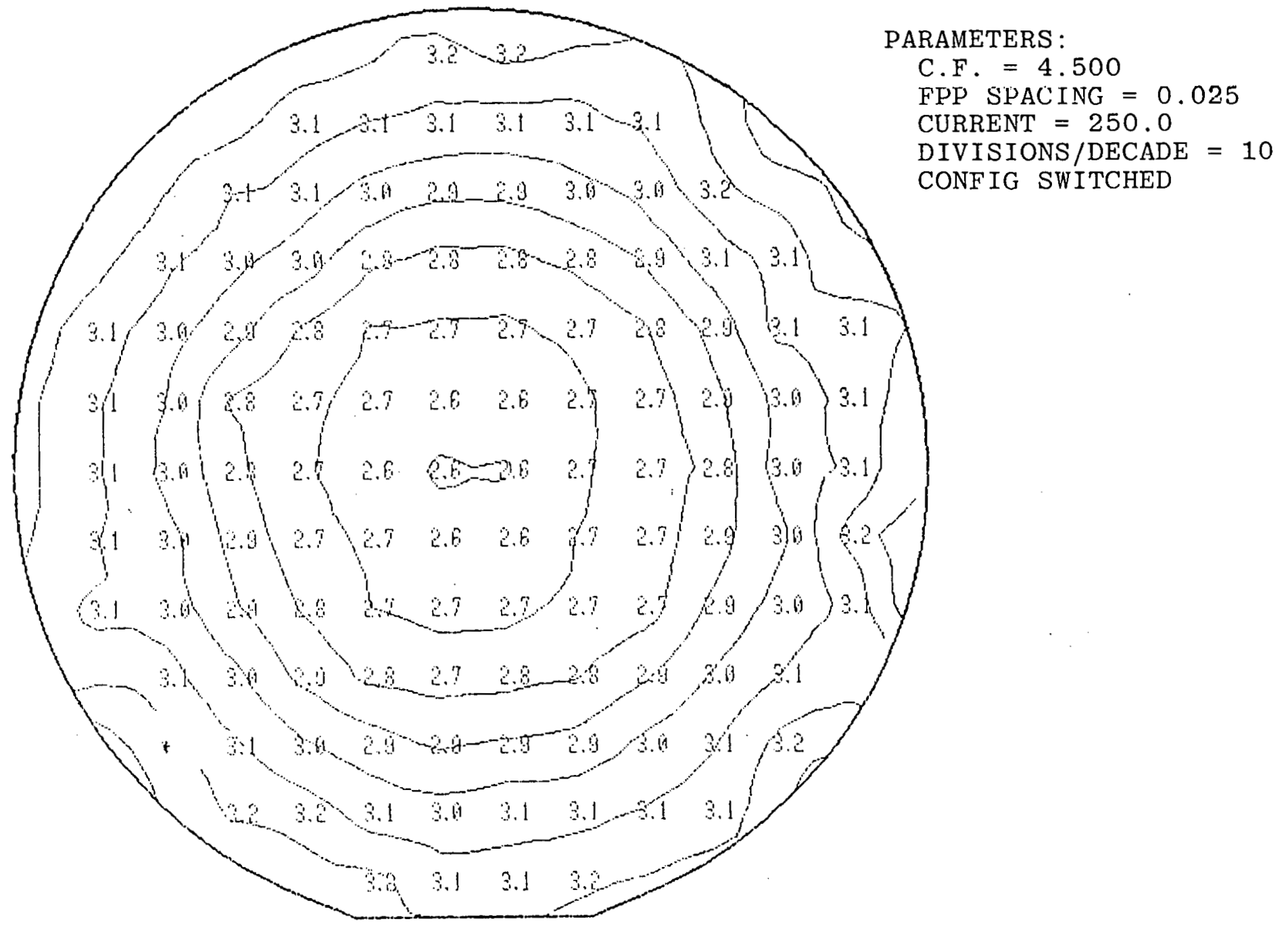

$930.36 \mathrm{ohm} / \mathrm{sq} . \pm 77.74 \%$

Log of Mean $^{-}=2.969$

Figure 2. Sheet Resistance Contour Map for Neutral

Beam Component only of. High Current Implanter After Ánnealing. 
implanters has been completed. The objective of this design specification was to provide a high throughput ion implantation system of commercial quality to demonstrate the feasibility of utilizing ion implantation in the large scale manufacturing of solar cells. The system specified will meet the general design requirements. Major system elements are:

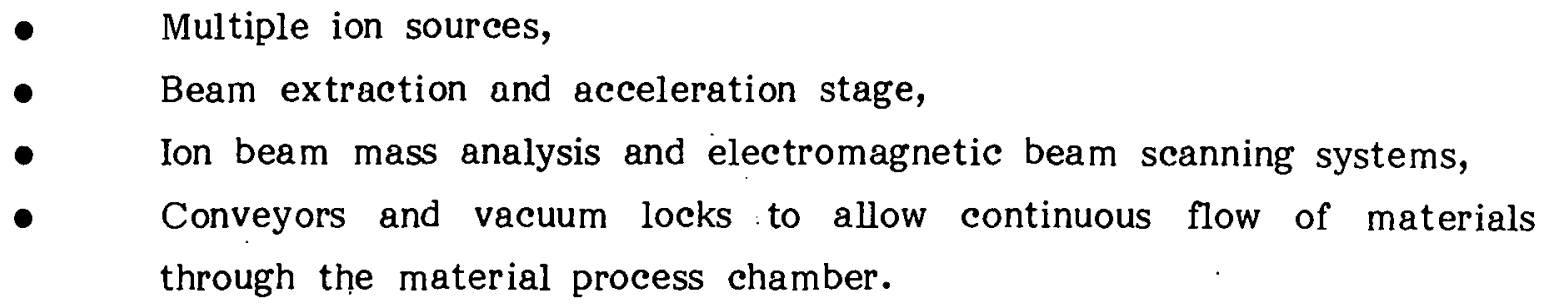

The materials to be processed will be fit into $22 \mathrm{~cm} \times 22 \mathrm{~cm}$ carriers used for transport through the system. Vacuum systems using diffusion pumps are provided to pump the gas from the ion sources and to pump the gases and vapors evolved by the substrate during passage through the target chamber. Additional pumping by mechanical vacuum pumps is provided to reduce the pressure from atmospheric to the operating pressure in the entrance and exit sections of the machine. Fast operating locks are used to prevent continuous gas flow into the system. A differential pumping arrangement could be incorporated for continuous flow.

\subsubsection{Major Subsystems in the Automated Ion Implanter}

The implanter includes power supply systems and computer control for the ion sources, mass analyzing magnet, and beam scanner system as shown in Figures 3 and 4 . These units are linked together by the signals from beam current measuring instrumentation which includes Faraday cages and multi-channel current metering. The proposed dose monitoring system is also capable of measuring the uniformity of the dose provided by each ion source system. The dose may be pre-set in the dose controller which automatically keeps the dose within specifications of $\pm 10 \%$. 


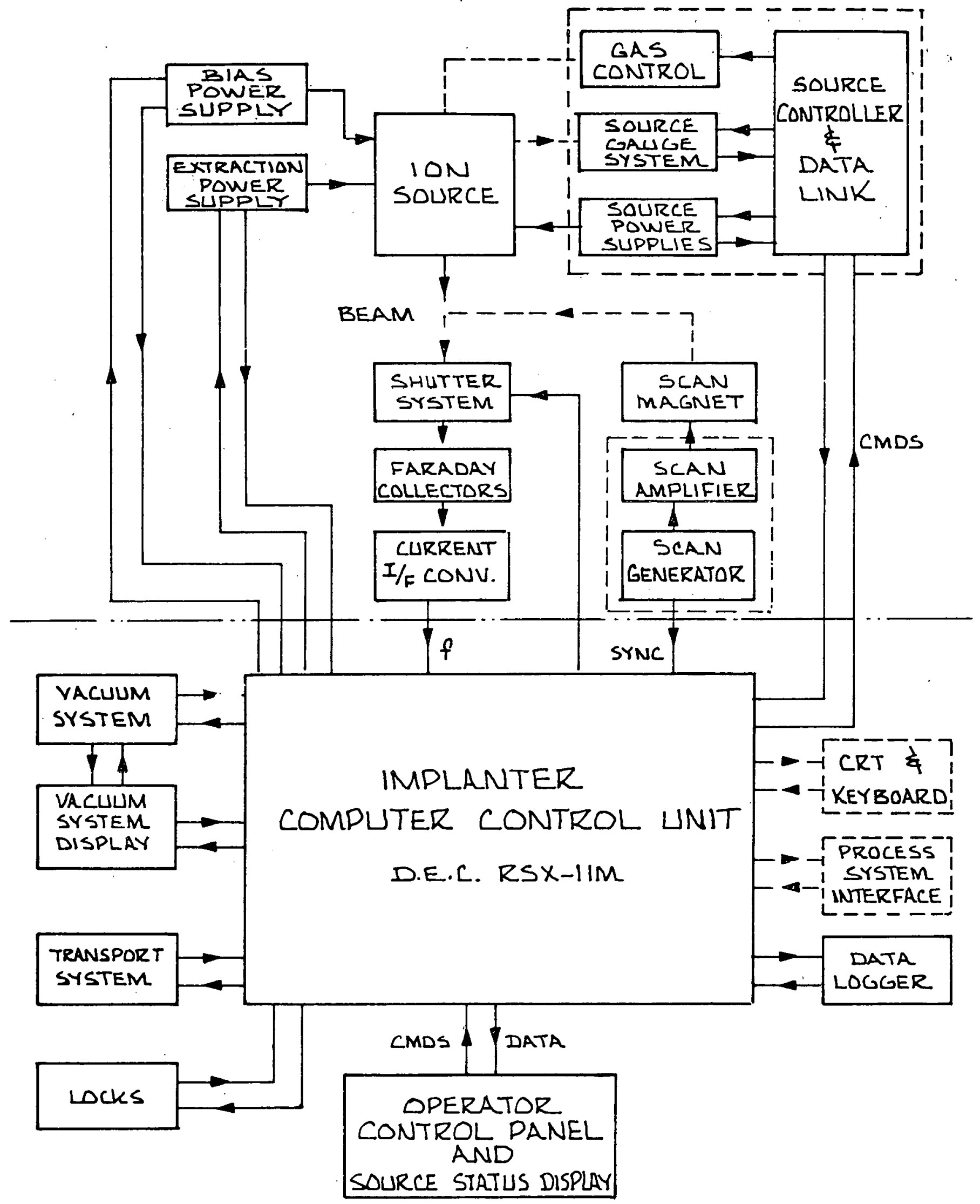

Figure 3. Vacuum Control System Block Diagram. 


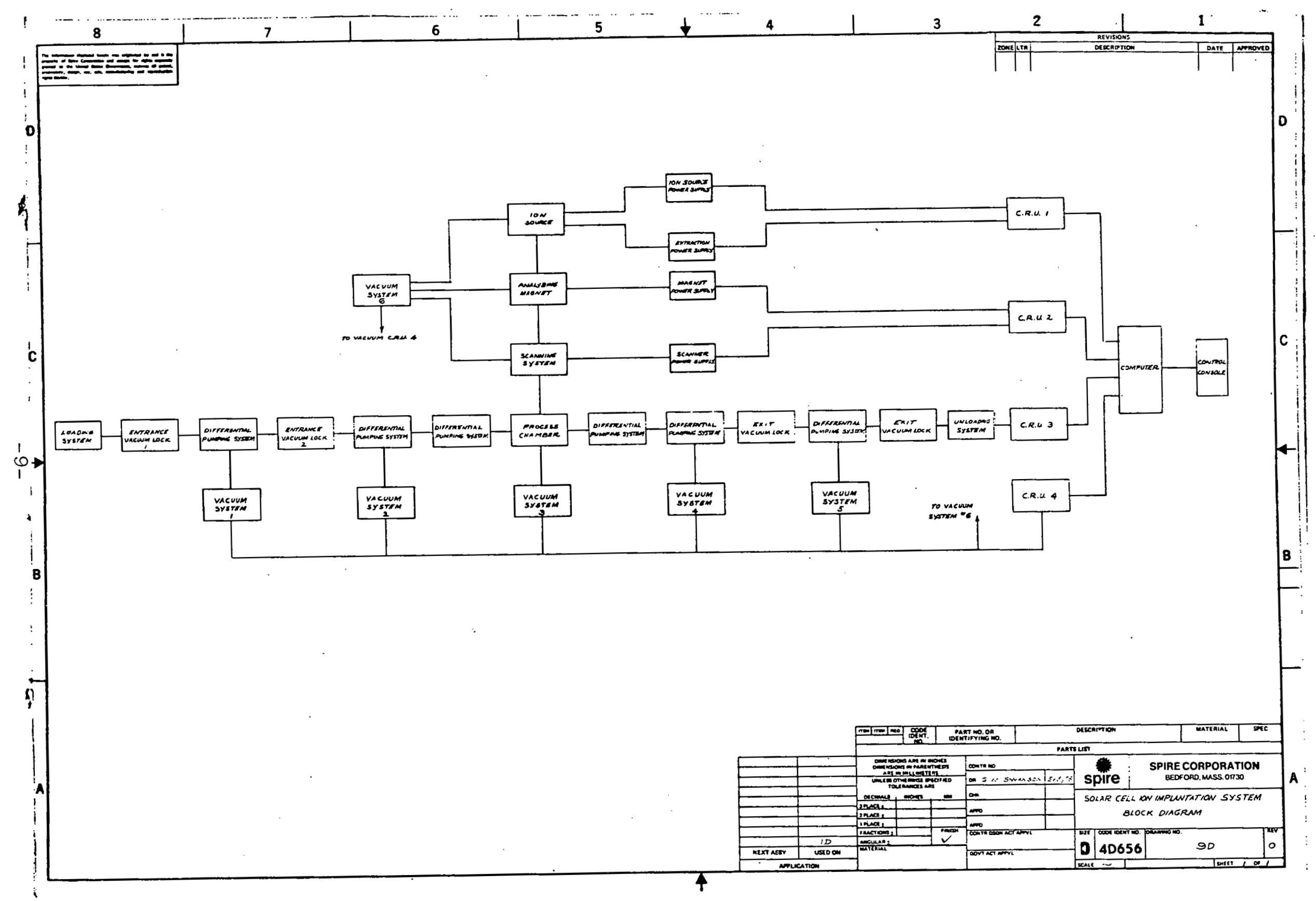

Figure 4. Solar Cell Ion Implantation System Block Diagram. 
The machine is fully automated, i.e. only one controller is needed to start or stop the implanter, once the setup conditions have been satisfied. A mini-computer is used to link together the various sub-systems and to provide controls, monitoring displays, and data storage.

\section{Ion Sources}

The ions are provided from arc discharge sources with exit apertures of 75 $\mathrm{mm}$ long by $2 \mathrm{~mm}$ wide, as shown in Figure 5 . The arc chamber is made of molybdenum and shaped to focus the beam from the source into the analyzing magnet gap with minimized loss of beam current. The ion sources are designed to operate on gases such as hydrogen diluted $\mathrm{PH}_{3}$, or in the case where boron ion beams are required, $\mathrm{BF}_{3}$. The design of the source and the source power supplies are such that it does not exclude a later modification to solid source vaporizers. The purposes for this modification would be first, to decrease the hazards of use of toxic gases, and second, to decrease the gas load on the vacuum system. An ion source can be removed from the system for maintenance and replacement while the implanter is running. Source gas feed, roughing system and power supplies are designed to be independent. Each source module is completely interlocked to prevent operational errors. The sources are designed to operate for 24 hours per day with a probability of failure of less than $1 \%$. The source is to be removed for filament replacement and maintenance within this 24 hour period. Each source is controlled by its own servo loop with monitoring instructions from the main control computer. All control displays and signals are isolated by optical fiber links.

Each ion source is designed to provide 20 milliamperes of analyzed ${ }^{31} \mathrm{p}^{+}$ beam. In order to process texturized silicon substrates, five sources can implant at any angle within $\pm 15^{\circ}$ from the normal. Typically three sources will operate at 16 milliamperes each and at $+15^{\circ}$ and three sources at the same current at $-15^{\circ}$. The additional four milliamperes will then be provided by a seventh ion source which provides a final dose control. 


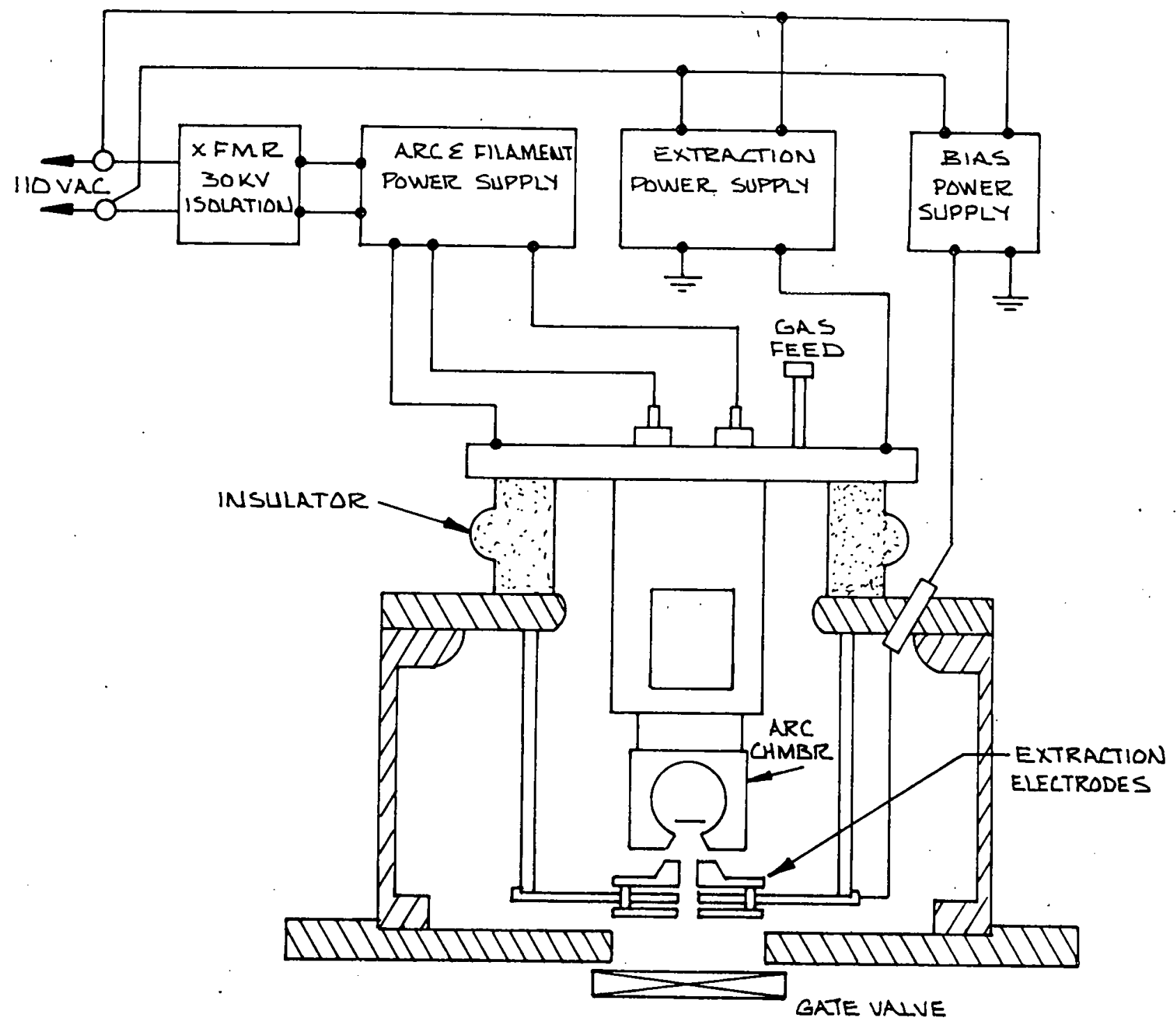

Figure 5. Ion Source and Source power Supplies Diagram. 


\section{Acceleration System}

The beam extraction system, which serves to accelerate ions from the source, is a single gap geometry with negatively biased electrodes to trap electrons. Each extraction supply has been rated to provide 50 milliamperes of current continuously. Supplies for each source are independently controlled and may be $\pm 2 \%$ about the predetermined value so that the position of the beam in the analyzing slit can be optimized for maximum beam current on target. In order to minimize neutral beam formation, a series of restrictions or apertures, one for each source, is placed ahead of the analyzer entrance pole face. After initial adjustment, the mechanical components can be removed for changing and cleaning and then returned to the original position using guide pins.

\section{Analyzing System}

As was shown in figure 6 , the beam enters the analyzer magnet pole face perpendicularly. The magnetic pole deflections of $\pm 45^{\circ}$ and $\pm 30^{\circ}$ are chosen to focus the beam on the target at an angle of $\pm 15^{\circ}$. The magnetic focussing system is designed such that the beam focusses at the analysis slits and in an orthogonal direction on the target. The radius of curvature of the beam trajectory in the magnetic field is $30 \mathrm{~cm}$.

The analyzing magnet is divided into two mirror image segments. This enables five sources to strike a target at $+15^{\circ}$ to the normal and the other five at $-15^{\circ}$. The magnet gap is $60 \mathrm{~mm}$ and the power required by both sections of the magnet is $60 \mathrm{~kW}$ when analyzing arsenic ions. The power supply for the magnet is not operator controlled, but may be adjusted internally to allow for a change of ion species or beam energy.

\section{Scanning System}

A magnetic scanning system with a laminated core has been designed in order to minimize the power required to scan the beam. The magnetic field gap is located in the region of the beam crossover. The minimum gap between the poles of the scanning magnet is $10 \mathrm{~mm}$. The magnet iron and drive coils are shielded from the ion beams and located in the vacuum of the analyzer tank. A scan 


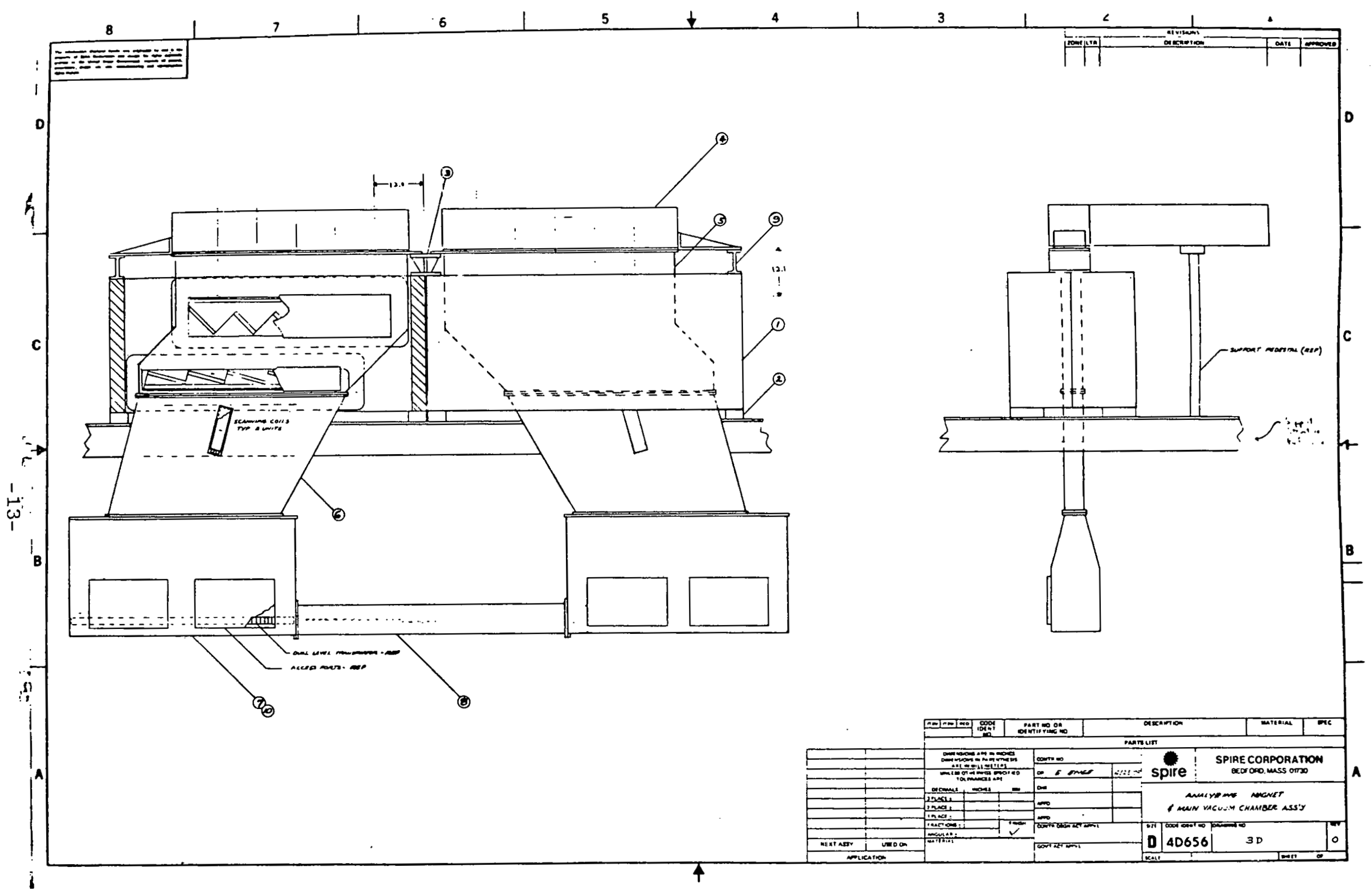

Figure 6. Analyzing Magnet \& Main Vacuum Chamber Assembly. 
generator is provided which can be adjusted to produce the correct wave form to satisfy the system uniformity requirements. The system has been designed to provide $+5 \%$ uniformity of dose which is well within the functional requirement of $\pm 10 \%$. A wide band amplifier has been selected to drive the system. It has a peak rating of $1.0 \mathrm{kVA}$. The mean position of the scanning magnet is $1200 \mathrm{~mm}$ below the exit of the analyzer magnet. Each scanner coil and magnet can be removed for repair and is coded with pins to prevent location in an incorreat opening. To change a scanner magnet, the main vacuum system must be vented to atmospheric pressure.

\section{Process Chamber}

The implant chamber has been designed to include a chain drive substrate carrier system. Carriers are fitted onto this chain at two levels from the entrance lock $115 \mathrm{~mm}$ below each other as shown in Figure 7. Three carriers at a time will pass through each level with a gap of $45 \mathrm{~mm}$ between the groups of three. The chamber is provided with a series of mechanical beam gates each with a Faraday cage and a system of eight slits for beam dose uniformity measurements and for beam scan adjustment. The beam gates are driven by stepping motors under control of the central computer. Cooling is provided for all parts of the system where necessary.

\section{Entrance and Exit Vacuum Locks}

The carriers are transported through the system in a sequenced group of three at alternative levels, spaced vertically by $25 \mathrm{~mm}$ at the entrances and exits. There is a space between the sets of three in the longitudal direction of $45 \mathrm{~mm}$ to provide time for valve sequencing. The vacuum locks are closely synchronized to maintain the relative space between the carriers which prevents jamming and vacuum failure. The speed of the system is nominally $30 \mathrm{~cm}$ per second but can be varied between the maximum speed of $40 \mathrm{~cm}$ per second down to $5 \mathrm{~cm}$ per second by adjusting the speed of the d.c. drive motor. The carrier system was designed so that it is operating from this motor using mechanical means to move the belt of the carrier drive along the length of the machine. The lock valves were designed to open and close within 0.1 second, and to be individually and 


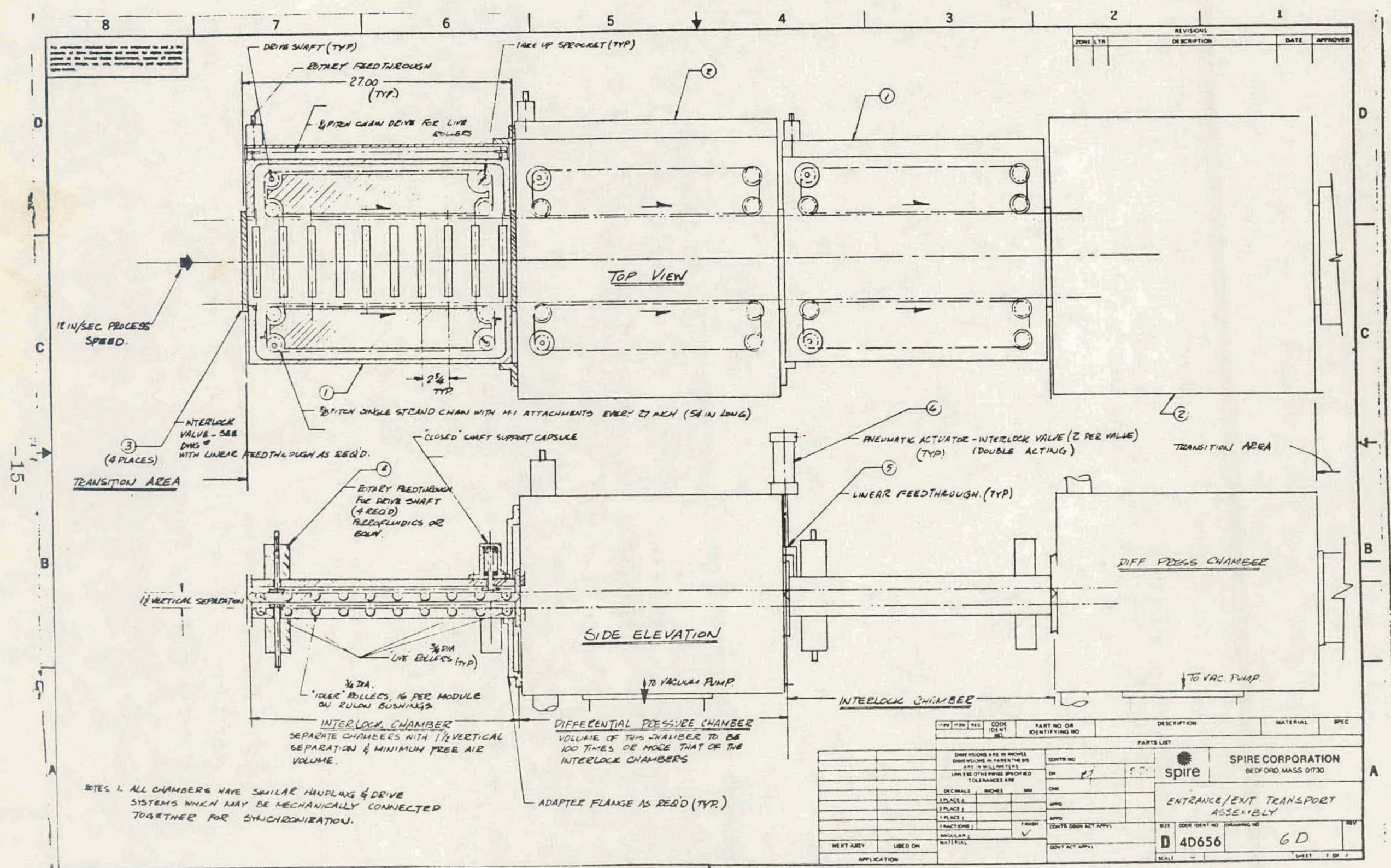

Figure 7. Entrance/Exit Transport Assembly. 
quickly serviced. The pumping is provided by a 1,000 liter per second Leybold-Hereaus Roots blowers type pump which pumps a plenum after each of the two vacuum lock systems. Each plenum must have a small volume of approximately 28 liters to allow rapid pump down between the second lock system and the process chamber. There is also a gas restriction channel. This channel is provided with a port to enable an extra stage of differential pumping to be employed if it is necessary. The vacuum lock system is designed to reduce the influx of dry nitrogen into the process chamber to less than 500 liters per second at the operating pressure at $5 \times 10^{-6}$ torr. Moist air is prevented from entering the implanter by a filtered hood system at the entrance and exit locks which are continuously purged with dry nitrogen. The cleanliness in this entrance region must be class 100 or better.

\section{Vacuum Systems}

The vacuum system can be divided into different regional categories which depend on the degree of vacuum required and the function to be performed as is shown in Figure 8.

The high vacuum system comprising the ion source chambers, the analyzing section, and the process chamber should, when sealed from the rest of the system, be capable of reaching a base pressure of $5 \times 10^{-7}$ torr. To make this possible the major parts of the vacuum system are constructed of stainless steel which have been cleaned by the Diversy process or some equivalent technique. The mild steel (magnet poles) in the vacuum system must be carefully cleaned and free from inclusions of virtual leaks. It may be necessary to electroplate or coat the mild steel poles with a corrosion resistant material such as nickel to prevent out-gassing. Viton gaskets are used as a vacuum seal in this and in all other parts of the vacuum system. The analyzer and process chambers are pumped by large diffusion pumps.

The source gas system design specifies stainless steel and other corrosion resistant materials such as ceramics. The gas lines are designed to minimize the hazards associated with toxic gases. A specially designed protective gas venting 


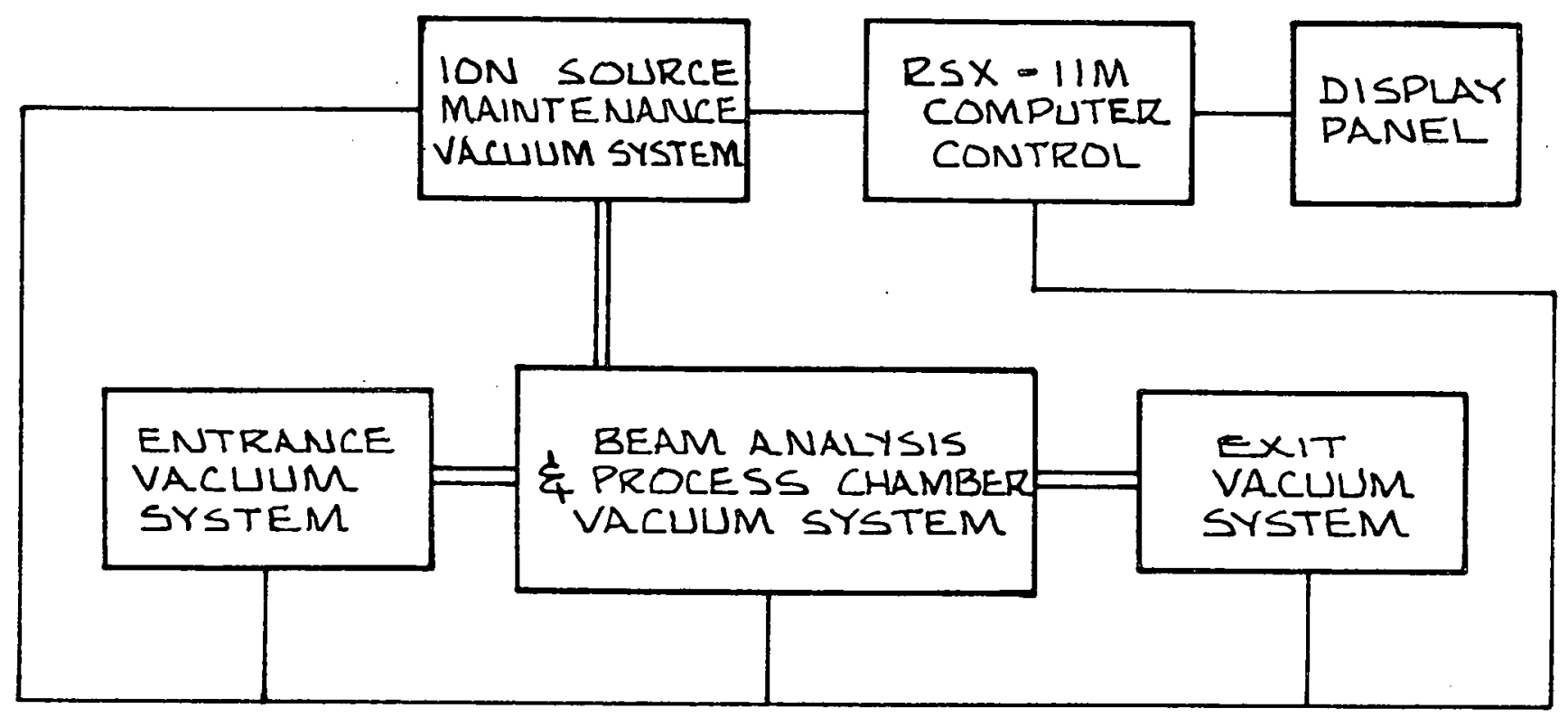

Figure 8. Vacuum System Block Diagram. 
system is provicied. The source roughing system is fabricated from brazed copper pipe and brass or stainless steel bellows valves. Flange couplings are provided where necessary to enable the system to be disassembled for cleaning. Stainless steel bellows valves are provided between each source chamber and the roughing valve for vibration isolation of the mechanical pumps. The lock chambers arefabricated of stainless steel and must be cleaned by an electro-chemical means. The chains and chain drives can be constructed of ordinary steel. Some lubrication using a low vapor pressure grease is allowed in this transport area.

The moving mechanical parts inside the vacuum system are designed to operate without maintenance for at least 2000 hours. The Roots blowers are coupled directly to pumping plenums without vibration isolation. Viewing ports are provided for inspection of the system during operation. The entrances and exits were designed to be identical except with changes dictated by the different direction of material flow.

A roughing and dry nitrogen bleed system is provided for system maintenance. A rough down time in the main chamber to a pressure of 30 microns is estimated to be about 20 minutes. The vacuum system is designed to cycle from atmosphere to the operating condition automatically under control of the main computer. The necessary read-outs and interlocks are to be provided to make this possible. Certain valves have positive indication of closure to prevent the accidental presence of a carrier of substrate material. In addition, because of the continuous and rapid flow of material through the system, clutches and other devices are provided to stop the system and prevent catastrophic vacuum failure. The carrier system must be capable of being brought to rest in three seconds. Routine vacuum maintenance should be provided on the vacuum equipment according to the manufacturer's regular requirements. Fore-pump fluids: can be changed without machine down time. Changing diffusion pump oil and cleaning the analyzer and process chamber will take not more than 24 hours. 
Substrate Carriers

The substrate carriers shown in Figure 9 are made of aluminum plate and have dimensions of $210 \mathrm{~mm} \times 210 \mathrm{~mm} \times 6 \mathrm{~mm}\left(8.375^{\prime \prime}\right.$ by $\left.0.25^{\prime \prime}\right)$. The plate material will be selected for a low out gassing rate. After manufacture, the surfaces must be polished and cleaned. It then may be necessary to keep the carriers in dry nitrogen at a temperature of $10^{\circ} \mathrm{C}$ above room temperature prior to use.

\section{Control Console}

The implanter control console is to be connected to the implanter by a 5 meter long armoured cable. The console consists of three 2 meter high cabinets connected together and provided with a desk. The console has the main operating control panel which enables an operator to start up processing and shut down the machine without any other actions. Two display panels indicate the status of the ion sources in the vacuum system. The display is such that a fault condition is indicated by a red light and an audible alarm is sounded. The computer system specified is a Digital Equipment Corporation RSX-11M. The computer system selected for the prototype implanter system is also suitable for software development and includes the following components:

- $11 / 34$ A CPU $(32 \mathrm{~kW})$
- $\quad$ A serial line unit
-
-
-
RL11-AK disk cont-AK drive
LA11-PA printer

All communications to and from the computer will be via fiber optic isolators.

The system software has been designed to minimize the initial requirements. The control circuitry was designed so that the servo loops are at their lowest level. Software programs will be written initially for: 


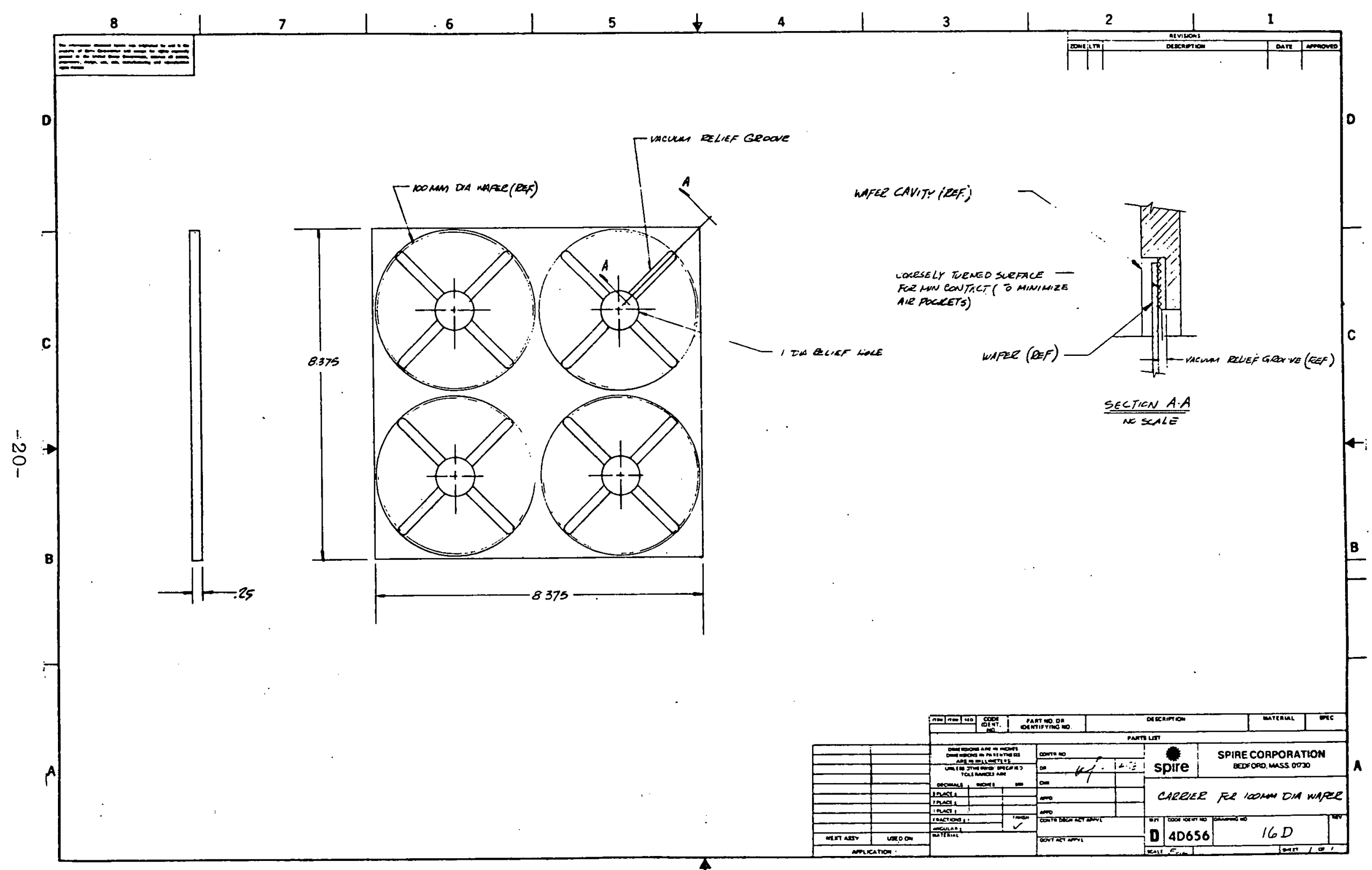

Figure 9. Carrier for 100 M Diameter wafer. 


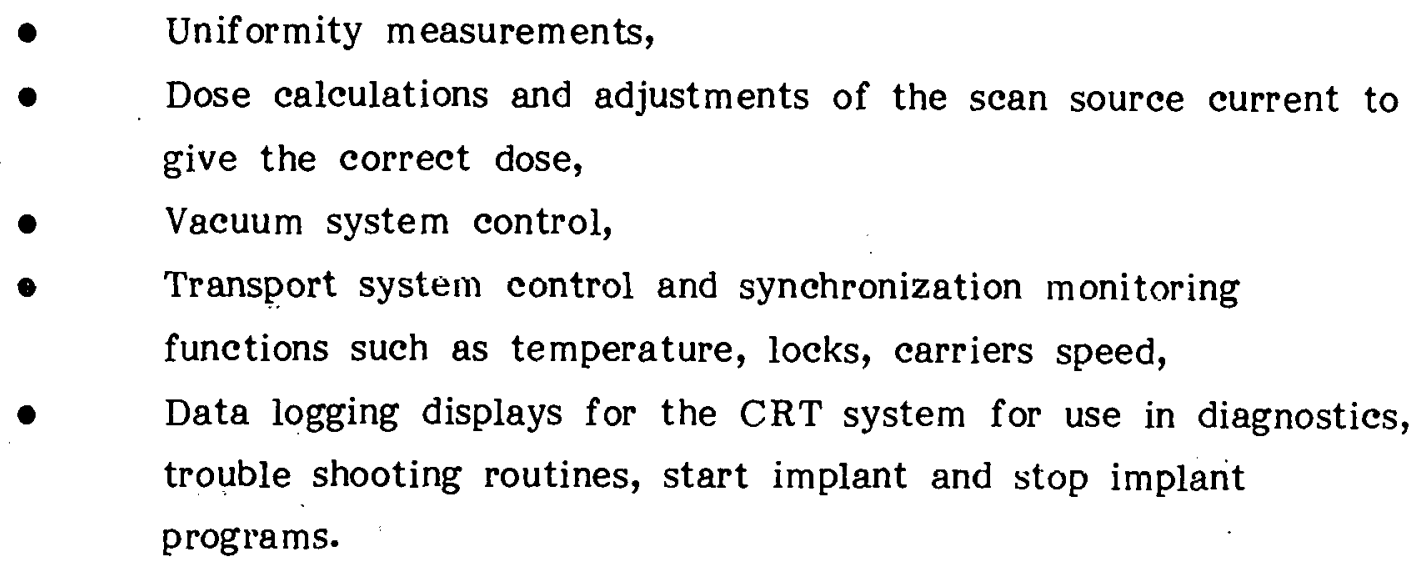

\subsection{ECONOMIC CHARACTERIZATION OF ION IMPLANTATION}

In order to provide the information necessary to adequately assess relative economic potential of ion implantation; a SAMICS economic analysis was performed.

This analysis has been done according to the JPL SAMICS Format A for ion implantation of solar cell junctions. Input data for a semiconductor type ion implanter, a Varian/Extrion model 200-20A, and a state-of-the-art solar cell processor implanter were obtained from experience. These data include:

i) Ion implanter facility labor requirements, material utilization and energy consumption.

ii) Process yield performance distribution and product throughput.

Input data for the advanced automated production ion implanter were obtained from design development efforts for the 100 milliampere implanter. Results show a decreasing cost in dollars per watt as the ion beam current is increased from microampere to milliampere levels as is shown in Table $\mathrm{I}$. This analysis shows that with a 100 milliampere automated production system the cost in dollars per square meter is 1.28 (in 1975 dollars) for 1986 production levels. Based on a conversion efficiency of $10 \%$ AM1, this results in a cost of less than $1 \Phi$ per watt. 
TABLE 1

SUMMARY OF SAMICS ANALYSIS

FOR ION IMPLANTED JUNCTIONS

\begin{tabular}{|c|c|c|c|c|c|}
\hline \multirow{2}{*}{ Implanter } & \multirow{2}{*}{$\begin{array}{l}\text { Ion Beam } \\
\text { Current } \\
(\mathrm{mA})\end{array}$} & \multirow{2}{*}{$\begin{array}{c}\text { Production } \\
\text { Year }\end{array}$} & \multirow{2}{*}{$\begin{array}{l}\text { Annual } \\
\text { Amount } \\
\mathrm{M}^{2} / \text { Year }\end{array}$} & \multicolumn{2}{|c|}{ Price $\left(\$ / M^{2}\right)$} \\
\hline & & & & $\begin{array}{l}\text { Production } \\
\text { Year Dollars }\end{array}$ & 1975 Dollars \\
\hline $\begin{array}{l}\text { Varian } \\
\text { Extrion } 200-20 \mathrm{~A}\end{array}$ & $0.1-0.2$ & 1978 & $5.6 \times 10^{3}$ & $1.01 \times 10^{3}$ & $8.36 \times 10^{2}$ \\
\hline $\begin{array}{l}\text { Varian/Extrion } \\
\text { Model 200-1000W }\end{array}$ & $2-4$ & $\begin{array}{l}1982 \\
1986\end{array}$ & $\begin{array}{l}8.0 \times 10^{4} \\
1.7 \times 10^{6}\end{array}$ & $\begin{array}{l}55.67 \\
68.35\end{array}$ & $\begin{array}{l}36.65 \\
35.63\end{array}$ \\
\hline $\begin{array}{l}\text { Automated } \\
\text { Production } \\
\text { System }\end{array}$ & 100 & $\begin{array}{l}1982 \\
1986\end{array}$ & $\begin{array}{l}8.0 \times 10^{4} \\
1.7 \times 10^{6}\end{array}$ & $\begin{array}{r}16.58 \\
2.46\end{array}$ & $\begin{array}{r}10.09 \\
1.28\end{array}$ \\
\hline
\end{tabular}


Additional economic analyses are being performed to assess costs of candidate annealing techniques. These cost estimates will identify the added cost for annealing of ion implantation damage using either furnace annealing with various time schedules or pulse annealing with various throughputs. 
THIS PAGE

\section{WAS INTENTIONALLY \\ LEFT BL'ANK}




\section{SECTION III}

\section{SOLAR CELL PROCESS DEVELOPMENT}

\section{$3: 1 \quad$ OBJECTIVE}

In order to assess and advance the technical status of ion implantation for silicon solar cells and to integrate implantation processing into a simplified approach for automated production of the highest efficiency cells, the following tasks are being performed under this program:

i) Modification of the cell design structure for improved performance using implantation for $\mathrm{n}^{+}$and $\mathrm{p}^{+}$dopant introduction.

ii) Assessment of relative performance of otherwise identical cells with diffused and ion implanted junctions and back surface fields.

iii) Integration of high performance cell structures into an abbreviated implantation/pulsed energy processing sequence being developed for low cost automated production.

\subsection{DEVELOPMENT OF PROCESSES FOR ION IMPLANTED PULSED ANNEALED SOLAR CELLS}

During this quarter, two process elements have been investigated for use in an in-line vacuum process. First, boron implants for $\mathrm{p}^{+}$back surface fields (BSF) have been successfully pulsed annealed and included in a pulse process cell structure. The back surface field effect had been demonstrated under this program earlier by the use of boron ion implantation and furnace annealing. Second, the use of polycrystalline cast silicon material has been investigated, and feasibility has been shown for use of polycrystalline material with ion implantation and pulsed electron beam manufacturing processing.

Pulse annealed, boron implanted back surface fields have been demonstrated to be effective in increasing $V_{\text {oc }}$ of $10 \mathrm{ohm}-\mathrm{cm}$ crucible grown silicon substrates from $550 \mathrm{mV}$ to $570 \mathrm{mV}$. Comparable back surface field effects after optimized furnace annealed boron ion implants increase $V_{\text {oc }}$ from $550 \mathrm{mV}$ to $585 \mathrm{mV}$. In these experiments, $5 \times 10^{15} / \mathrm{cm}^{2}$ boron ions were implanted at $25 \mathrm{keV}$ into the back 
surface of each wafer. The implants were then pulse annealed using a fluence of approximately $0.3 \mathrm{cal} / \mathrm{cm}^{2}$ for a 0.1 microsecond pulsed electron beam. Following pulse annealing of the ${ }^{1 \mathrm{~B}^{+}}$implant, the front junction was implanted with $2.5 \mathrm{x}$ $10^{15} 3 \mathrm{l} \mathrm{P}^{+} / \mathrm{cm}^{2}$ at $10 \mathrm{keV}$ and pulse annealed with an electron beam fluence of 0.2 $\mathrm{cal} / \mathrm{cm}^{2}$. Typical I-V characteristics of cells processed without furnace heat treatment but using only pulse annealing are shown in Figure 10. Cell efficiencies have been measured at $11.8 \%$ under AMO conditions.

Higher efficiency cells may be achievable with pulse annealing because of superior annealing character as was discussed in the second quarterly report. Rapid dopant diffusion during pulse anneal may result in a better junction profile. During pulse annealing, the bulk silicon remains at ambient temperature thereby precluding lifetime degradation by thermally induced defects. In addition, the cost of pulse processing of ion implantation damage annealing is considerably less than conventional furnace processing because of rapid throughput and the absence of wet chemistry and consumables. Pulse process annealing is also amenable to automation and very comparable with ion implantation since common cassettes can be implemented.

\subsection{CAST POLYCRYSTALLINE SHEET SOLAR CELLS}

Non-single crystal silicon materials have been investigated for use in solar cells produced by ion implantation, furnace annealing, and pulse annealing. Experimental data has been obtained for ion implanted $\mathrm{n}^{+} \mathrm{pp}{ }^{+}$solar cells. The cell process sequence was as outlined below:

- Bright Etch

- Implant front $2 \times 10^{15} \mathrm{P}^{31+} / \mathrm{cm}^{2}, 10 \mathrm{keV} 10^{\circ}$,

- Implant back $5 \times 10^{15} \mathrm{~B}^{11+} / \mathrm{cm}^{2}, 25 \mathrm{keV}, 10^{\circ}$,

- Anneal $-550^{\circ} \mathrm{C}$ two hours plus $850^{\circ} \mathrm{C}-15$ minutes plus $550^{\circ} \mathrm{C}$ - two hours,

- Contacts front, chrome, gold, silver, back - aluminum, silver,

- ar $\mathrm{TiO}_{2}$,

- Saw to $5 \times 5 \mathrm{~cm}$ 


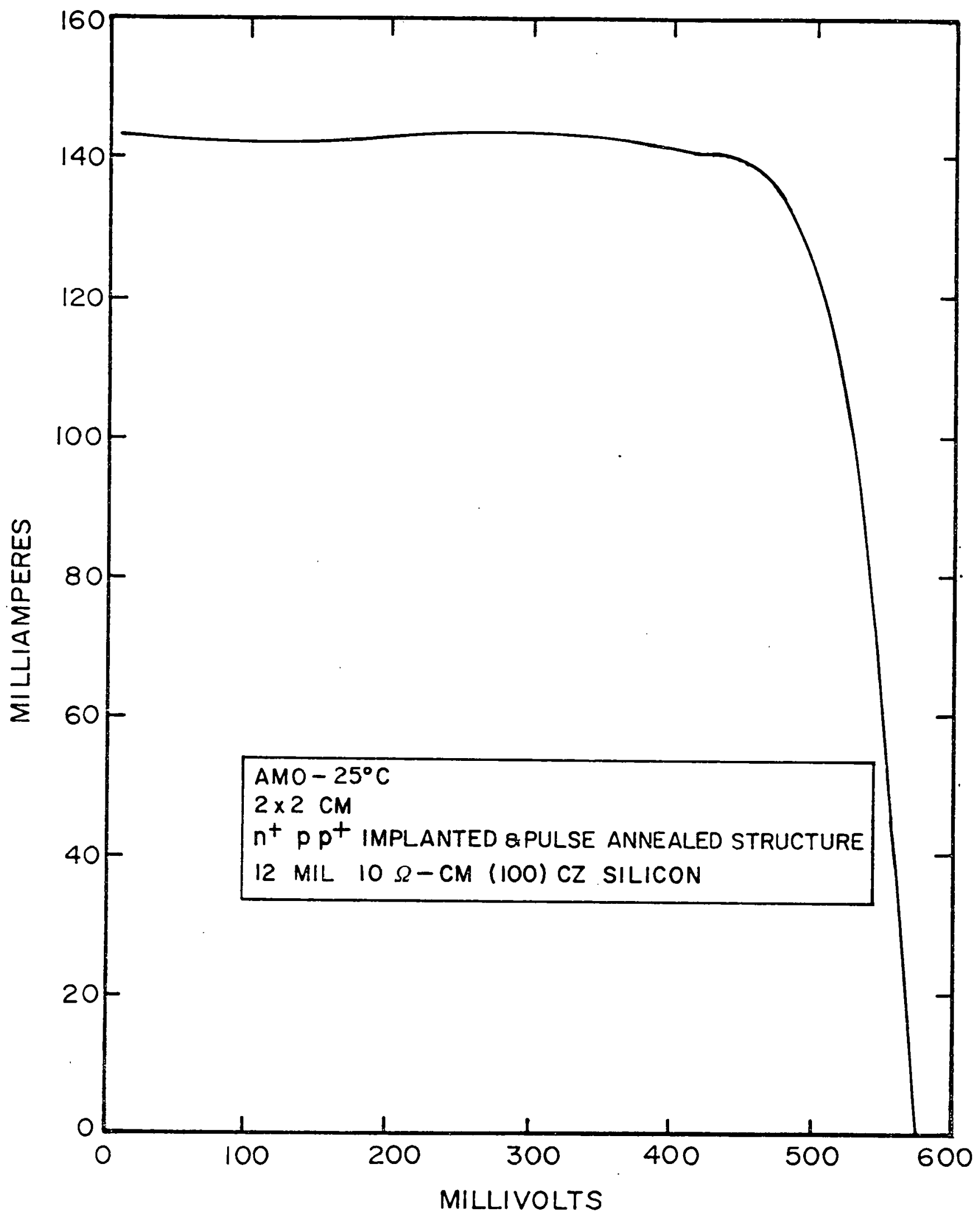

Figure 10. I-V Characteristics for Cells Processed Using Pulse Annealing of Both Phosphorus Junction and Boron BSF Implanted Layers. 
Typical electrical performance of polysrystalline cells with implanted junctions and $\mathrm{p}^{+}$layers is as shown in Figure 11 . The open circuit voltages is $540 \mathrm{mV}$ under AMO conditions, the current density is 30 milliamperes per $\mathrm{cm}^{2}$ and the cell efficiency is $9.5 \%$ AMO. In this case the $\mathrm{p}^{+}$boron implanted layer serves only as an ohmic contact because of the inadequate lifetime of the polycrystalline material. This is evidenced by non-enhancement of the open circuit voltage. Efforts are now emphasizing application of pulsed electron beam annealing of ion implantation damage in polycrystalline material. By using pulse processing it is believed that lifetime can be enhanced and as a result red response will increase.

The application of ion implantation to ribbon material has also been addressed. One preliminary test using furnace annealed ion implanted junctions described above has shown AMO efficiency of $5.2 \%$ on a $2 \times 2 \mathrm{~cm}$ test structure. This processing did not incorporate either a gettcring step or etching to remove surface silicon prior to processing, and as a result the red response of the device is poor. Further efforts will consider material removal prior to implantation. These tests do show that methods optimized for single crystal solar cells are applicable to polycrystalline sheet or ribbon materials. However, further process development is required to improve electrical performance.

\subsection{SOLAR CELL MANUFACTURING PROCESS COMPARISONS}

The second of three solar cell junction and BSF performance evaluations has been completed. The study has been performed to compare ion implantation and diffusion technology for dopant introduction. Starting material was (100) 10 ohm-cm crucible grown silicon with etched surfaces. Three groups of cells having both implanted and diffused junctions were processed as follows:

(i) Diffused junctions and back surface fields introduced at OCLI.

(ii) Furnace annealed, ion implanted back surface field and furnace annealed implanted junctions.

(iii) Furnaced annealed, implanted back surface field and pulse annealed implanted junctions. 


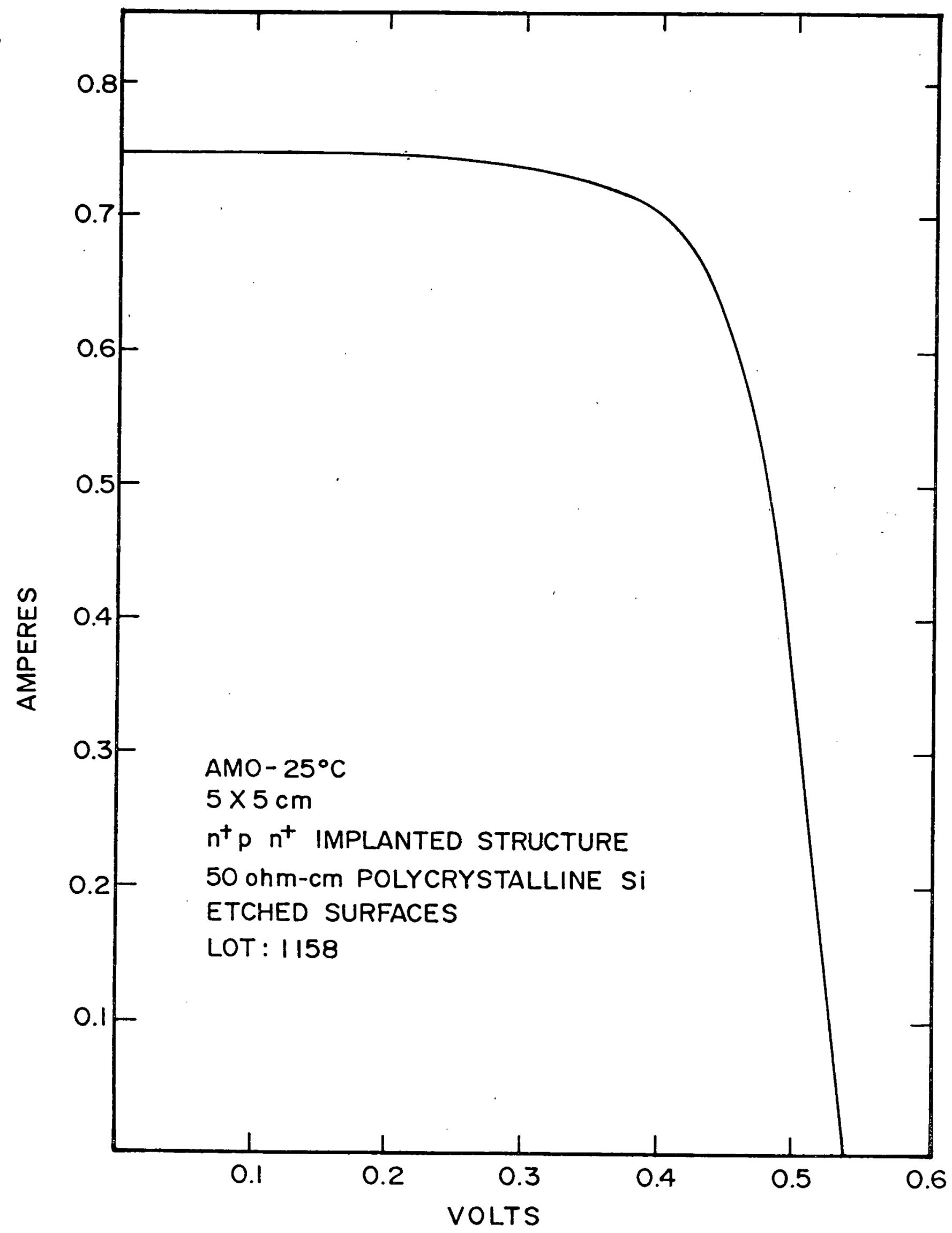

Figure 11. I-V Characteristics for Polycrystalline Cells with Implanted $\mathrm{n}+$ and $\mathrm{p}+$ Structure. 
The third type of cells employed furnace annealed back surface field layers because development efforts at the time of this comparison were still active to effectively pulse anneal the necessary boron implant. For all three types of processing, contacts, multiple layer AR coating and AMO performance measurements were completed at OCLI. Table II summarizes the peak and mean cell characteristics under AMO conditions for each type. Figures 12 through 20 show the open circuit voltage, short circuit current and maximum power performance distribution of each. Note that the highest short circuit currents were obtained by processing both the junction and the BSF by ion implantation and furnace annealing. The highest cell efficiency attained was $13.8 \%$ AMO for furnace annealed and $12.7 \%$ AMO for pulse annealed junctions.

The second process comparison utilized a violet cell grid design with ten lines per em to match the ion implanted junction layer sheet resistance. The third and final performance assessment will evaluate and compare both pulsed electron beam annealing and laser annealing of the junction layers. The back surface field layers to be incorporated in the $10 \mathrm{ohm}-\mathrm{cm}$ material will have been implanted and furnace annealed prior to implant of junction layer. As in previous performance assessments, OCLI will complete processing by applying contacts, AR coating, and then measuring cell performance.

Alternate pulsed energy sources such as lasers have been investigated at Spire for pulse annealing of the implanted phosphorous junction layers. Preliminary experimental data has been obtained for pulsed laser annealing and solar cell performance. The cell process sequence was as outlined below:

$\begin{array}{ll}\text { Silicon: } & 2 \text { ohm-cm }(100) \text { crucible grown } \\ \mathrm{p}^{+}: & 400 \text { angstroms aluminum alloyed at } 650^{\circ} \mathrm{C} \\ \mathrm{n}^{+}: & \text {Implant, } 2 \times 10^{15} 3 \mathrm{l}^{+} / \mathrm{cm}^{2} 10 \mathrm{keV} \\ & \text { Anneal, Pulsed } \mathrm{Nd}: \mathrm{YAG} \text { Laser } \\ \text { Contacts: } & \text { Front, } \mathrm{Cr}-\mathrm{Au}-\mathrm{Ag} \\ & \text { Back, } \mathrm{Al}-\mathrm{Ag} \\ \text { AR: } & \mathrm{TiO}_{2}\end{array}$


TABLE II

SUMMARY OF SECOND PERFORMANCE COMPARISON OF

CELL MANUFACTURING TECHNIQUES

\begin{tabular}{|c|c|c|c|c|c|c|c|}
\hline \multirow{3}{*}{$\begin{array}{l}\text { Junction } \\
\text { and BSF } \\
\text { Formation }\end{array}$} & \multicolumn{6}{|c|}{ AMO- $25^{\circ} \mathrm{C}$ Performance } & \multirow{3}{*}{$\begin{array}{l}\text { No. of } \\
\text { Cells }\end{array}$} \\
\hline & \multicolumn{2}{|c|}{ Isc $(m A)$} & \multicolumn{2}{|c|}{ Voc $(\mathrm{mV})$} & \multicolumn{2}{|c|}{$P_{450}(\mathrm{~m} \mathrm{~W})$} & \\
\hline & Average & Peak & Average & Peak & Average & Peak & \\
\hline $\begin{array}{l}\text { Diffused } \\
\text { and Alloy }\end{array}$ & 157 & 162 & 589 & $59 y$ & 62.4 & 66.3 & 67 \\
\hline $\begin{array}{l}\text { Implant/ } \\
\text { Furnace Anneal }\end{array}$ & 157 & 165 & 564 & 582 & 64.2 & 71.9 & 80 \\
\hline $\begin{array}{l}\text { Implant/ } \\
\text { Pulse Anneal }\end{array}$ & 154 & 158 & 563 & 571 & 58.4 & 68.8 & 79 \\
\hline
\end{tabular}




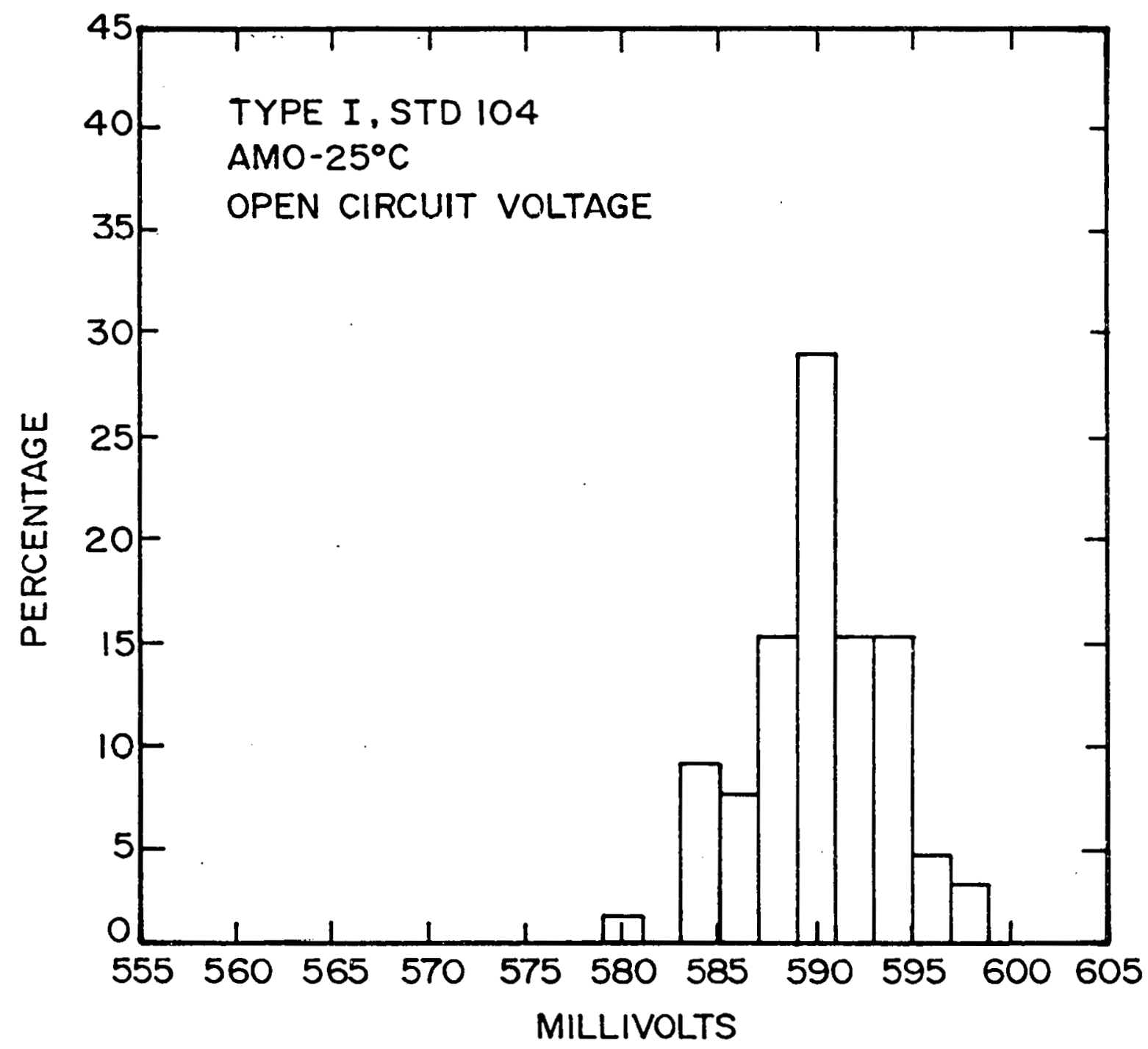

Figure 12. Distribution of $\mathrm{V}_{\text {or }}$ for Diffused Junction and Alloyed BSF Test Cells. 


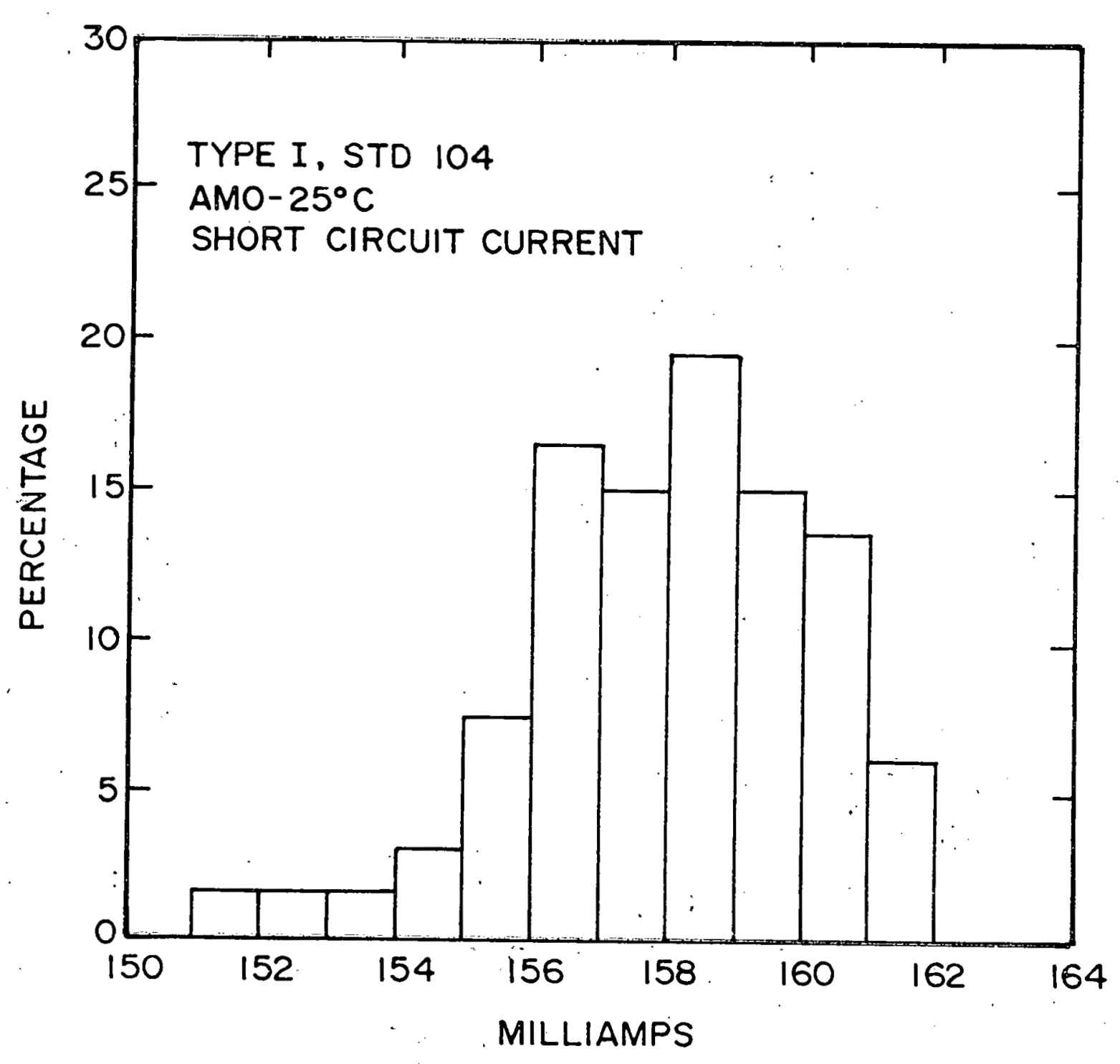

Figure 13. Distribution of $I_{S c}$ for Diffused Junction and Alloyed BSF Test Cells. 


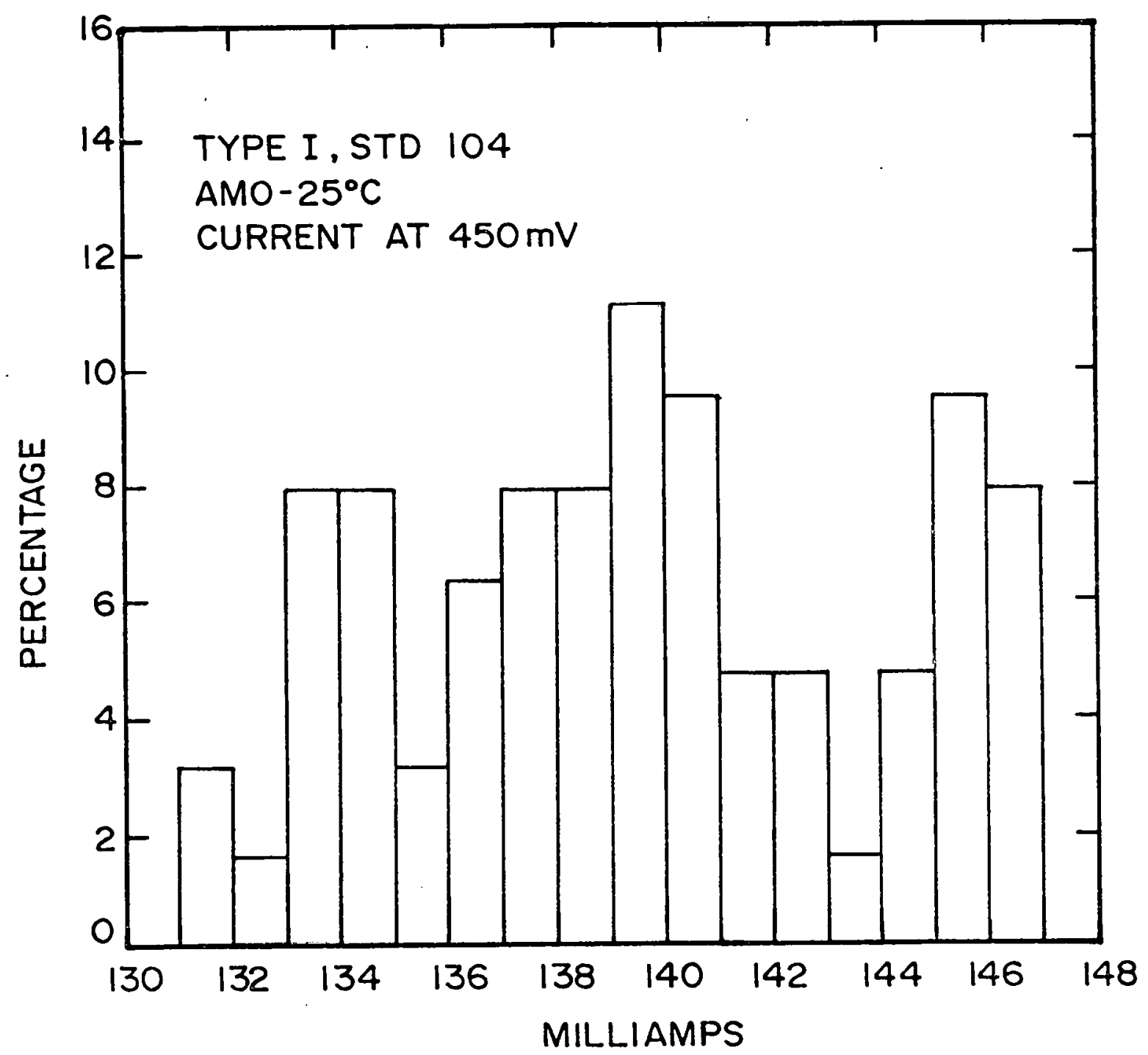

Figure 14. Distribution of $\mathrm{I}_{450}$ for Diffused Junction and Alloyed BSF Cells. 


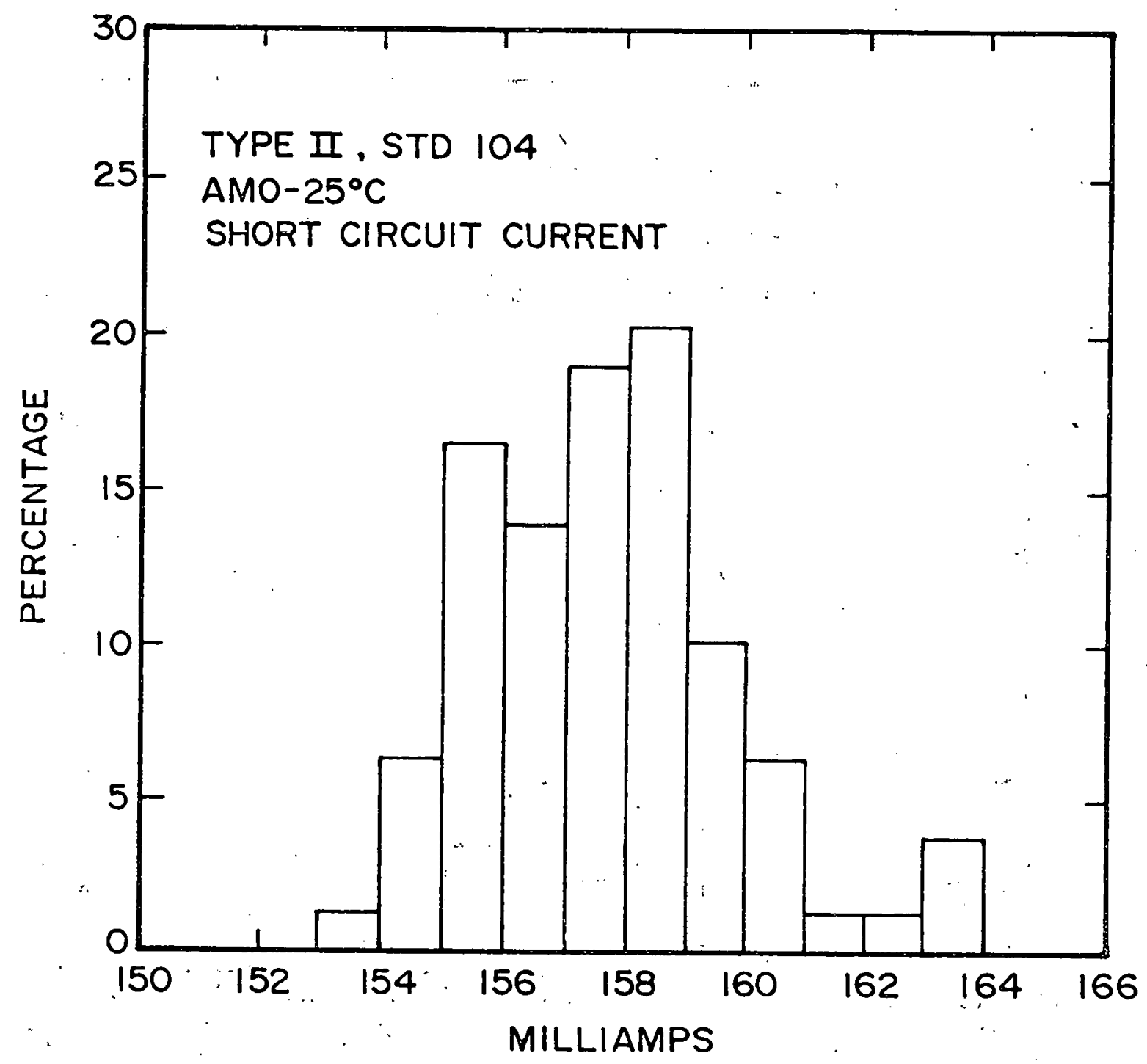

Figure 15. Distribution of $I_{S C}$ for Implanted and Furnace Annealed Junctions and BSF Test Cells. 


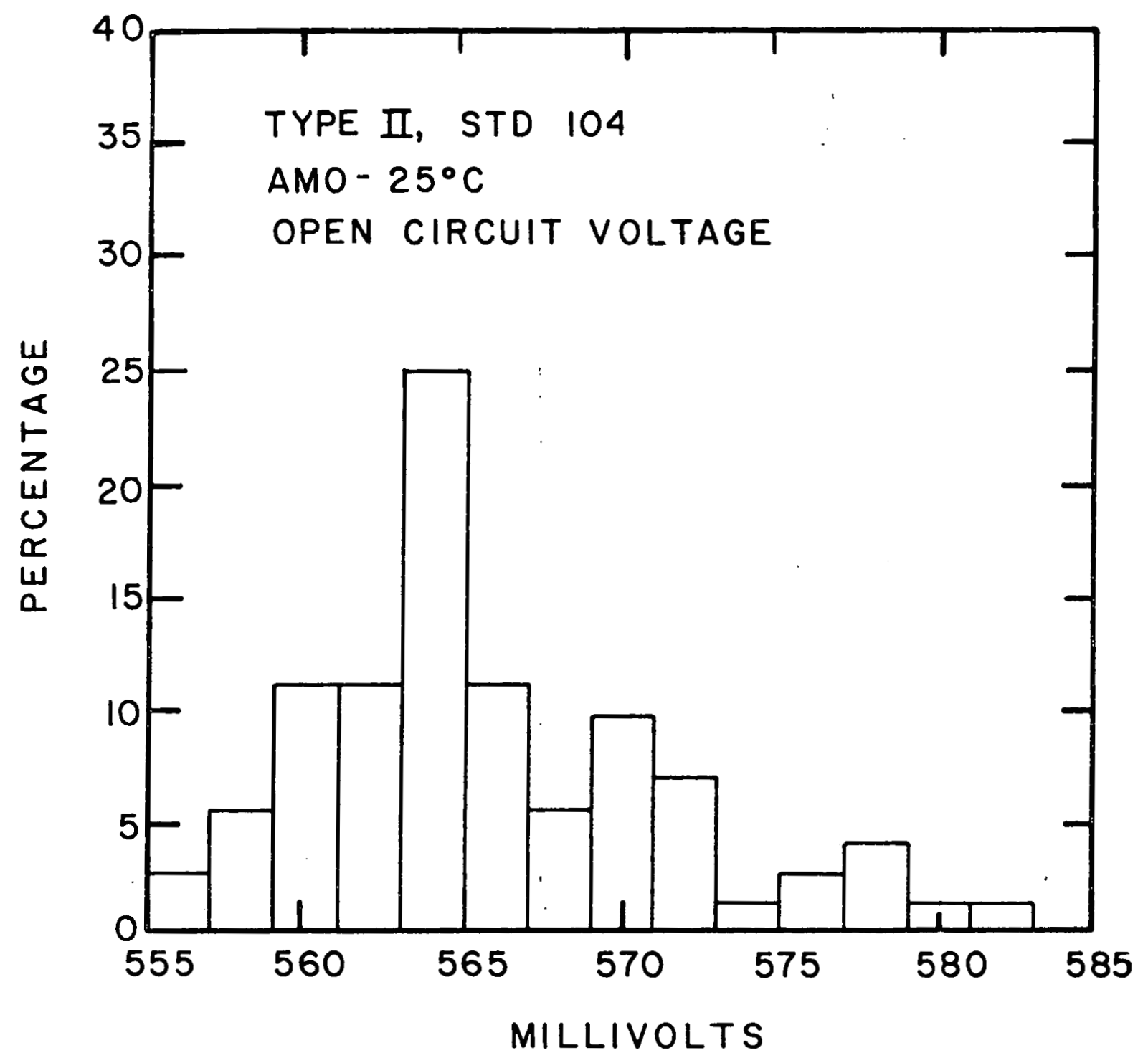

Figure 16. Distribution of $V_{o c}$ for Implanted and Furnace Annealed Junctions and BSF Test Cells. 


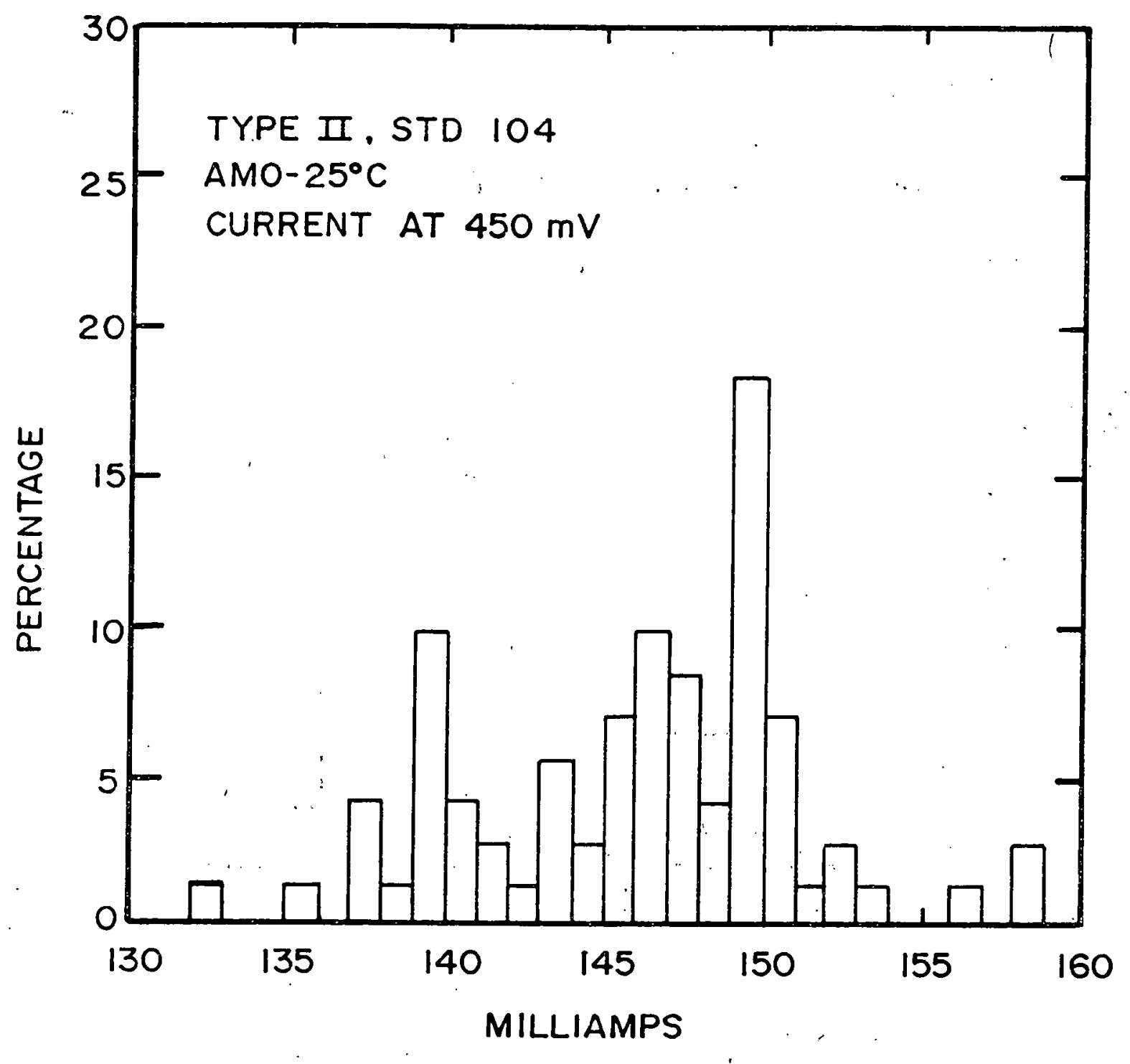

Figure 17. Distribution of $\mathrm{I}_{450}$ for Implanted and Furnace Annealed Junction and BSF Test Cells. 


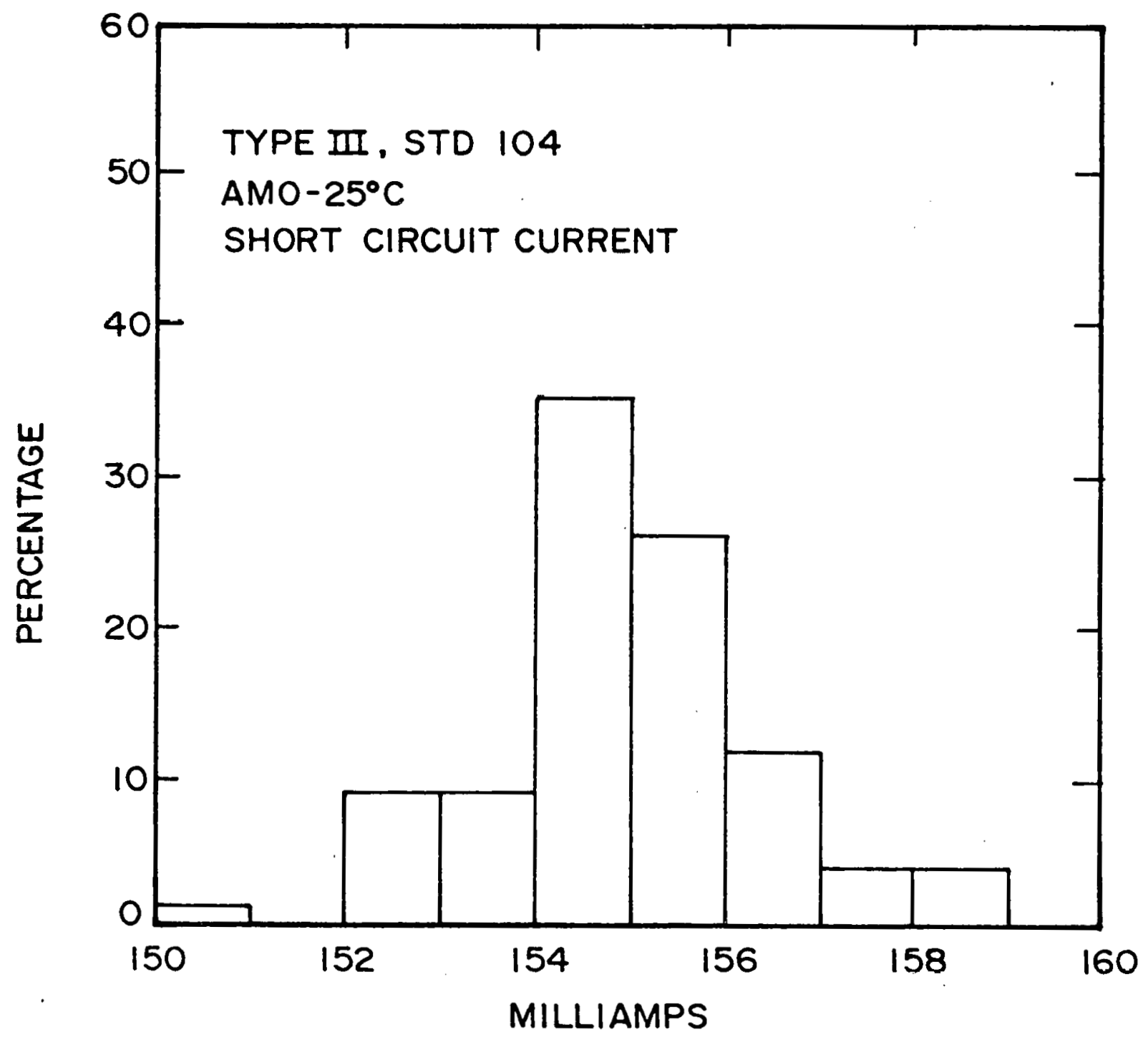

Figure 18. Distribution of $I_{s c}$ for Implanted/Furnace Annealed BSF and Implanted/Pulse Annealed Junction Test Cells. 


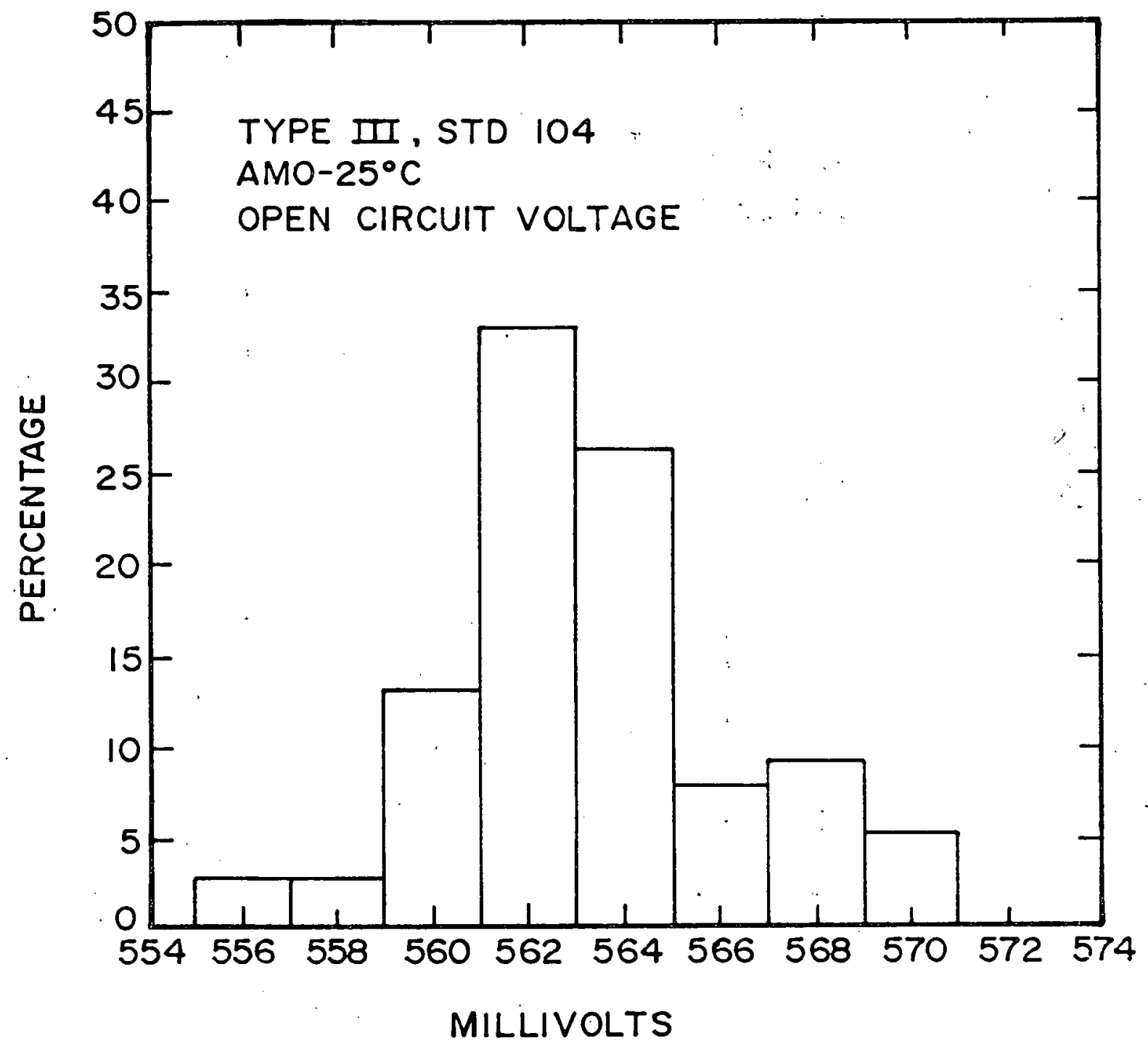

Figure 19. Distribution of $\mathrm{V}_{\text {oc }}$ Ion Implanted/Furnace Annealed BSF and Implanted/Pulse Annealed Junction Test Cells. 


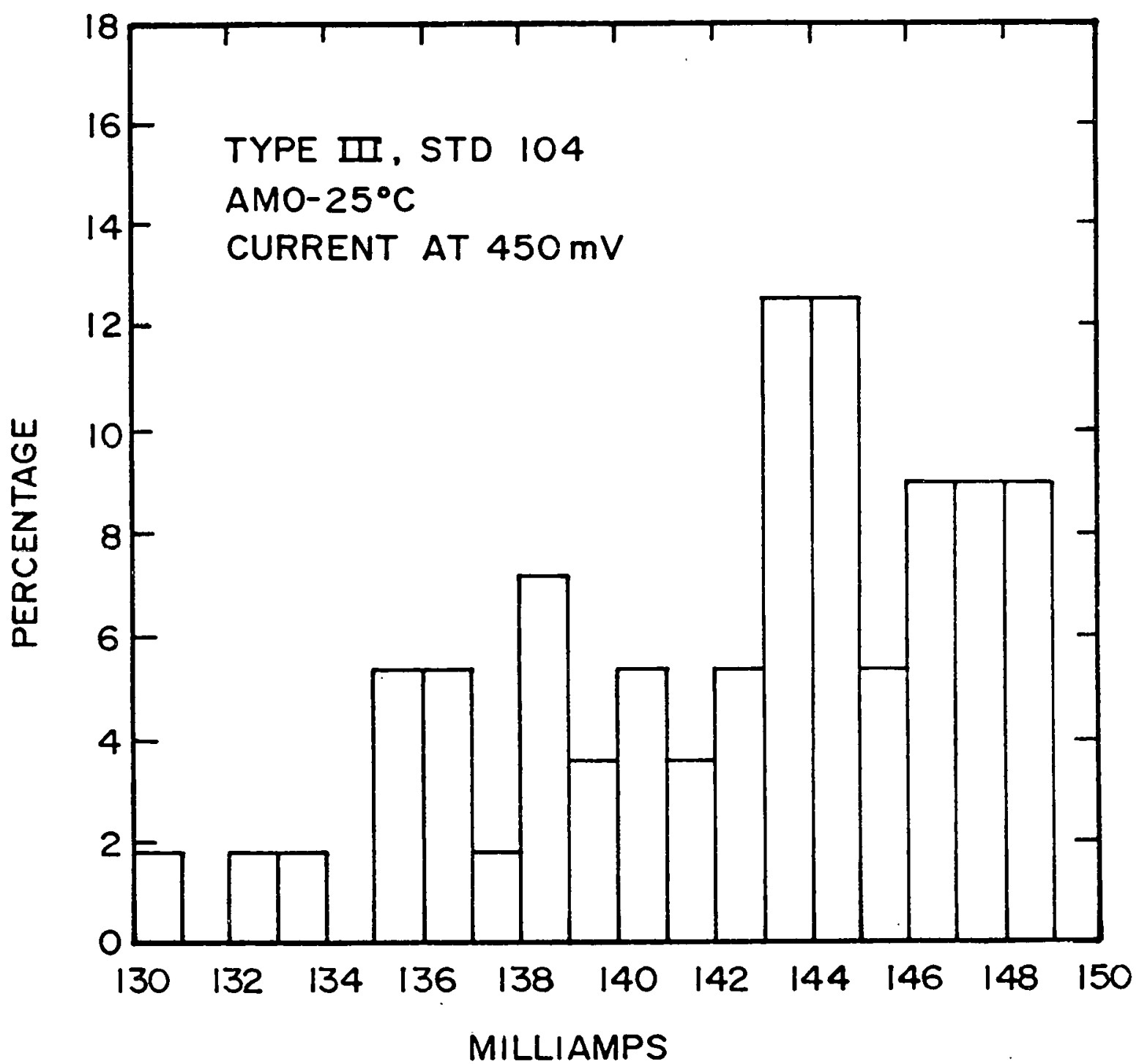

Figure 20. Distribution of $\mathrm{I}_{450}$ for Implanted/Furnace Annealed BSF and Implanted/Pulse Annealed Junction Test Cells. 
No additional furnace annealing was incorporated in this process following laser pulse annealing. Laser parameters used were as follows:

- Wavelength: Nd:YAG at 1.06 microns
- $\quad$ Pulse width: $20-50$ nanoseconds
-
-
-
-
-

Typical electrical performance of cells with laser annealed, ion implanted junctions is shown in Figure 21. The open circuit voltage is $570 \mathrm{mV}$ under AMO conditions. The cells show a similar Voc performance loss as previously obtained with pulsed electron beam annealing of implants without post pulse, low temperature annealing. Cell efficiencies have been measured at $9.2 \%$ AMO. For comparison and reference the best cells with electron beam pulse annealed junctions show efficiencies up to $12.3 \%$ AMO with the same cell structure. 


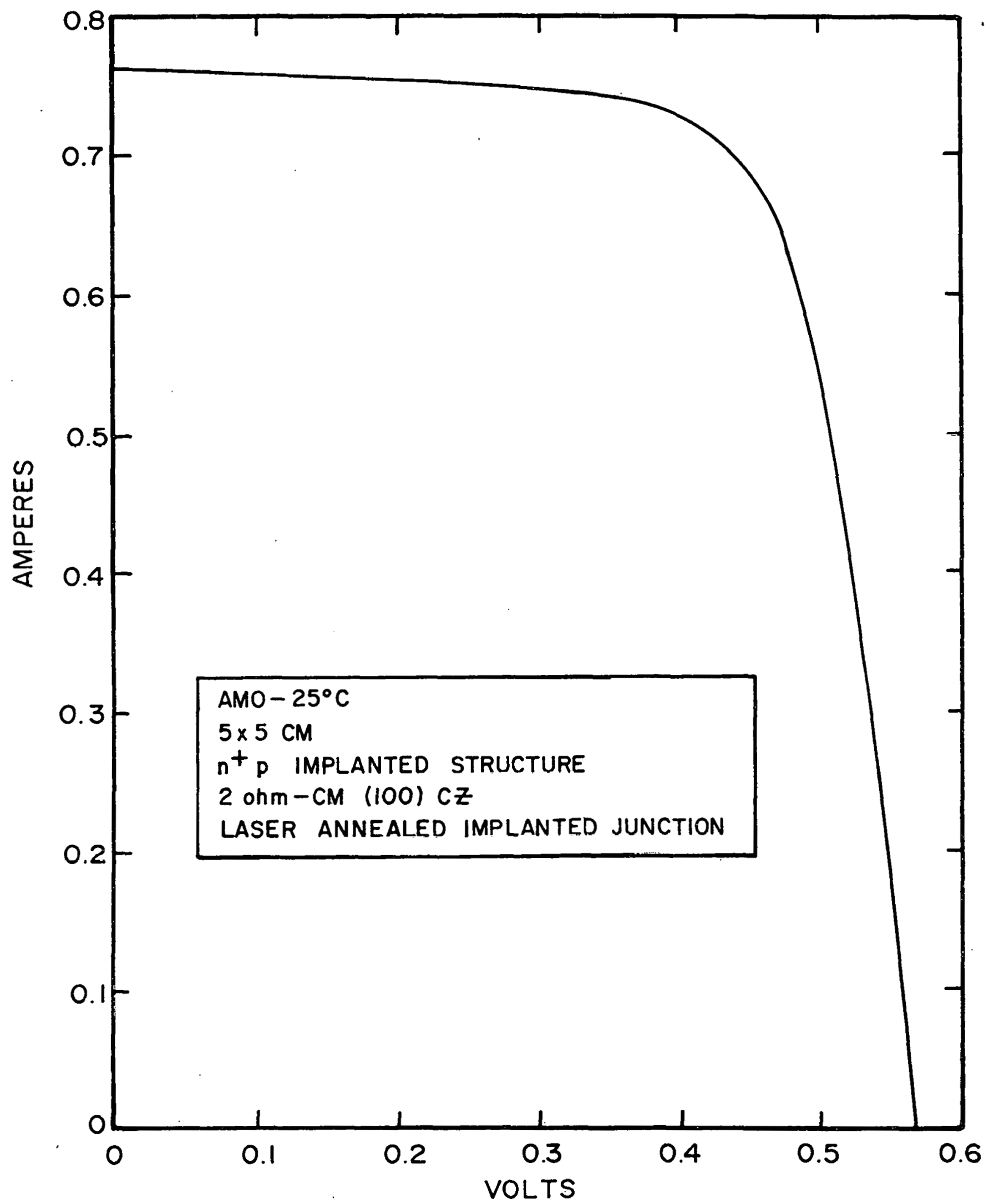

Figure 21. I-V Characteristics for Cells Processed Using Pulsed Nd:Yag Laser Annealed Implanted Junctions and Alloyed p+ Layers. 


\section{SECTION IV \\ PULSED ENERGY PROCESSING STUDIES}

\subsection{OBJECTIVES}

The application of ion implantation to solar cell processing requires an annealing technique to remove inherent radiation damage of the silicon lattice. As discussed in earlier reports, the requirements for successful furnace annealing are dependent upon implant parameters. Another approach that can anneal implantation damage is to utilize pulsed energy deposition. In this technique, a pulsed energy source is directed onto the surfaces to be heated. Almost all of the energy carried by the pulse source is deposited into the first few microns of the surface being processed resulting in a momentary, high temperature transient. A mechanism which can explain the exceptional annealing effects obtained by pulsed energy transients was identified and described in the first quarterly report. Since then, detailed numerical calculations have been completed which support the model proposed. Energy sources such as pulsed electron beams and lasers can replace thermal operations conventionally performed in a furnace. In addition, the use of pulse processing has potential advantages which can result in higher cell efficiencies, tighter performance distribution, and lower processing costs.

\subsection{DEVELOPMENT OF A THEORETICAL MODEL OF PULSED ENERGY} PROCESSES

Using the damage thresholds for silicon which have been measured and an understanding of the mechanism of pulsed annealing, a theoretical analysis has been developed for pulse energy processing. The model is constrained by the requirements for producing the annealing effects without reaching damage thresholds in silicon.

To formulate the model, calculations were performed using a computer program and analytical methods to determined the stress levels produced in the silicon as a result of temperature gradients. Physical effects associated 
with a solid-liquid phase change have been integrated into a heat transfer equation using numerical techniques. The heat transfer equation along with proper boundary conditions allows computer calculations of temperatures of spatial grid points immediately adjacent to a melt interface. Other modifications that were made include: multiple slab material properties that can be entered as input data to model the effects of implanted layers on temperature profiles. Also each of the slabs in the deposit can be entered as input data to model the effects of phase changes on temperature profiles.

The configuration chosen for testing of the numerical calculations consisted of a two-material composite with a square electron beam deposition profile penetrating through half of the first material. This problem can be easily solved analytically for the equilibrium temperature distribution. The result can be compared with a numerical computer output for very long times, i.e. steady state equilibrium conditions.

The VXTEMP computer program has been used to determine the temperature profile generated by the standard pulsed electron beam at a fluence of 0.2 $\mathrm{cui} / \mathrm{cm}^{2}$. The deposition profile as used in this calculation is as shown in Figure 2\%. The actual deposition profile varies as a function of both time and depth due to the changing electron beam energy and current levels. For puposes of this calculation, the depth dose profile as a function of time was assumed not to change in shape and was assumed to vary in amplitude in a Gaussian fashion, i.e. where $\boldsymbol{S D}(\mathrm{x}, \mathrm{t}) \mathrm{dt}$ is shown in Figure 22. This approximation is supported by experiments performed earlier in the program.

The thermal parameters used in this study are as follows. The specific heat as a function of temperature, $\mathrm{C}(\mathrm{T})$, of both crystalline and amorphous silicon was assumed to vary as the crystalline value with

$$
C(T)=0.8628+8.3452 \times 10^{-5} T-\left(1.6243 \times 10^{4}\right) / T^{2}
$$




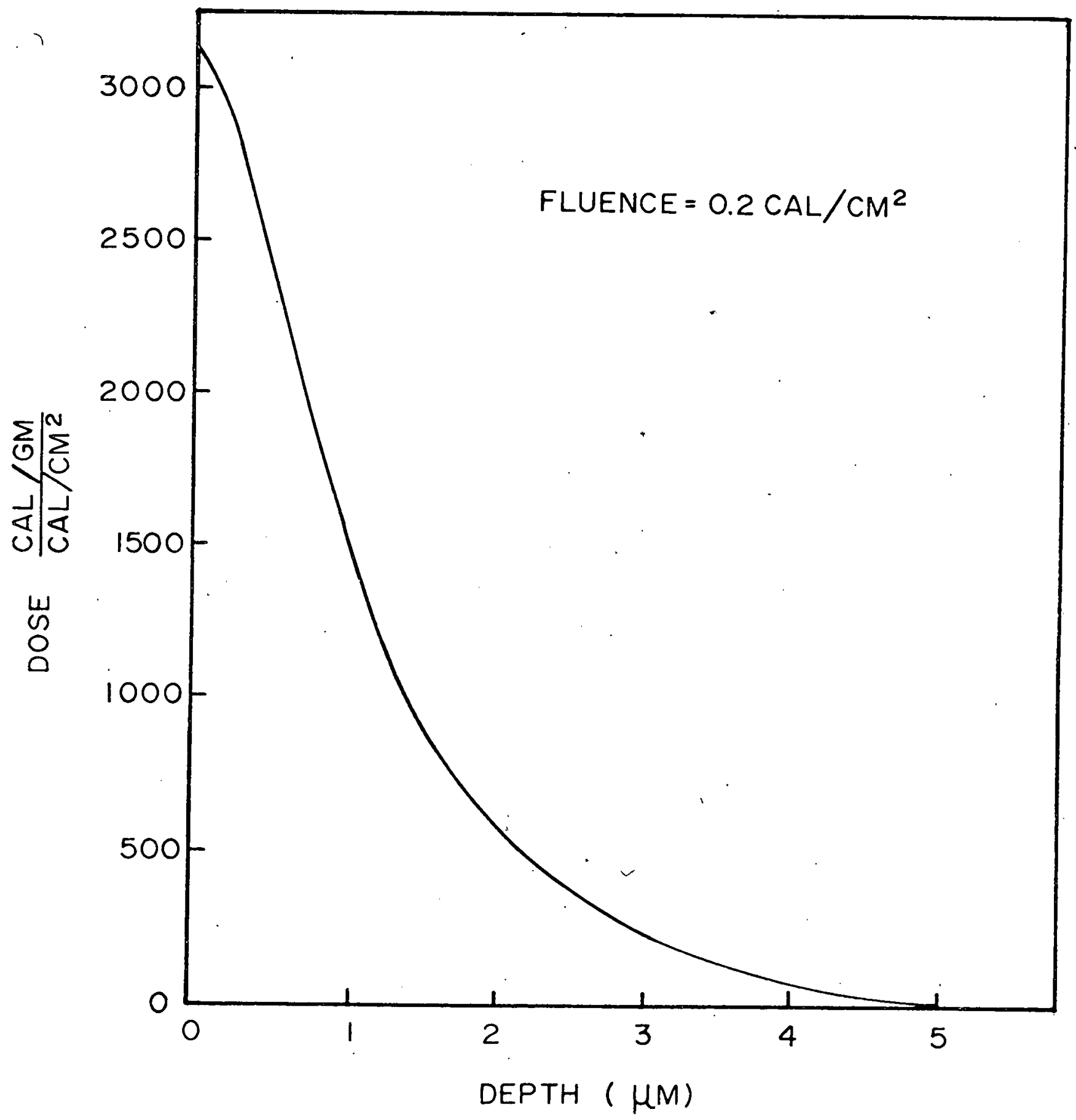

Figure 22. Energy Deposition vs. Depth Profile in Silicon for Pulsed Electron Beam. 
where $C(T)$ is in Joules/gram $-{ }^{\circ} \mathrm{K}$ and $\mathrm{T}$ is the temperature in degrees Kelvin. The variation of the thermal conductivity of the various silicon states is shown in Figure 23, with the amorphous values being estimated from fused quartz and crystal quartz analogs. Since we are assuming a glassy, amorphous layer with no heat of fusion during phase change, the melt and "pre-melt" thermal conductivity values for the amorphous layer were assumed equal.

The amorphous layer was assumed to be 0.1 micron thick, although ion channeling during implantation probably produces a semi-crystalline transition region between amorphous and crystalline material.

The results of the VXTEMP predictions are shown in Figures 24 through 26. The front surface temperature as a function of time is shown in Figure 24 . Note that the front surface does rise above melt, und because of the release of the latent heat of fusion upon cooling the surface stays at the melt temperature of $1410^{\circ} \mathrm{C}$ for approximately 175 nsec.

The in-depth temperature history profiles are shown in Figures 25 and 26. Note that the region above melt temperature expands to about 0.2 microns before starting to contract as cooling takes place. After about 175 nsec, the energy being deposited is very small since the injected electron beam pulse is almost complete except for the very low energy spike of decaying current, and thus the temperature starts to decline. As the melted silicon crystallizes, the heat of fusion is released $\left(\mathrm{H}_{\text {fusion }}=1803\right.$ Joules/gram). This effect keeps the first few tenths of microns at the melt temperature for more than an additional 100 nsec. After the front surface solidifies, the temperature drops rapidly, reaching the neighborhood of $600^{\circ} \mathrm{C}$ after a total elapsed time of about 600 nsec.

Stress calculations are in progress based on the temperature gradients predicted by VXTEMP. The measured micro-fracture levels of pure crystalline silicon in various crystal orientations seems to agree well with the differences in 


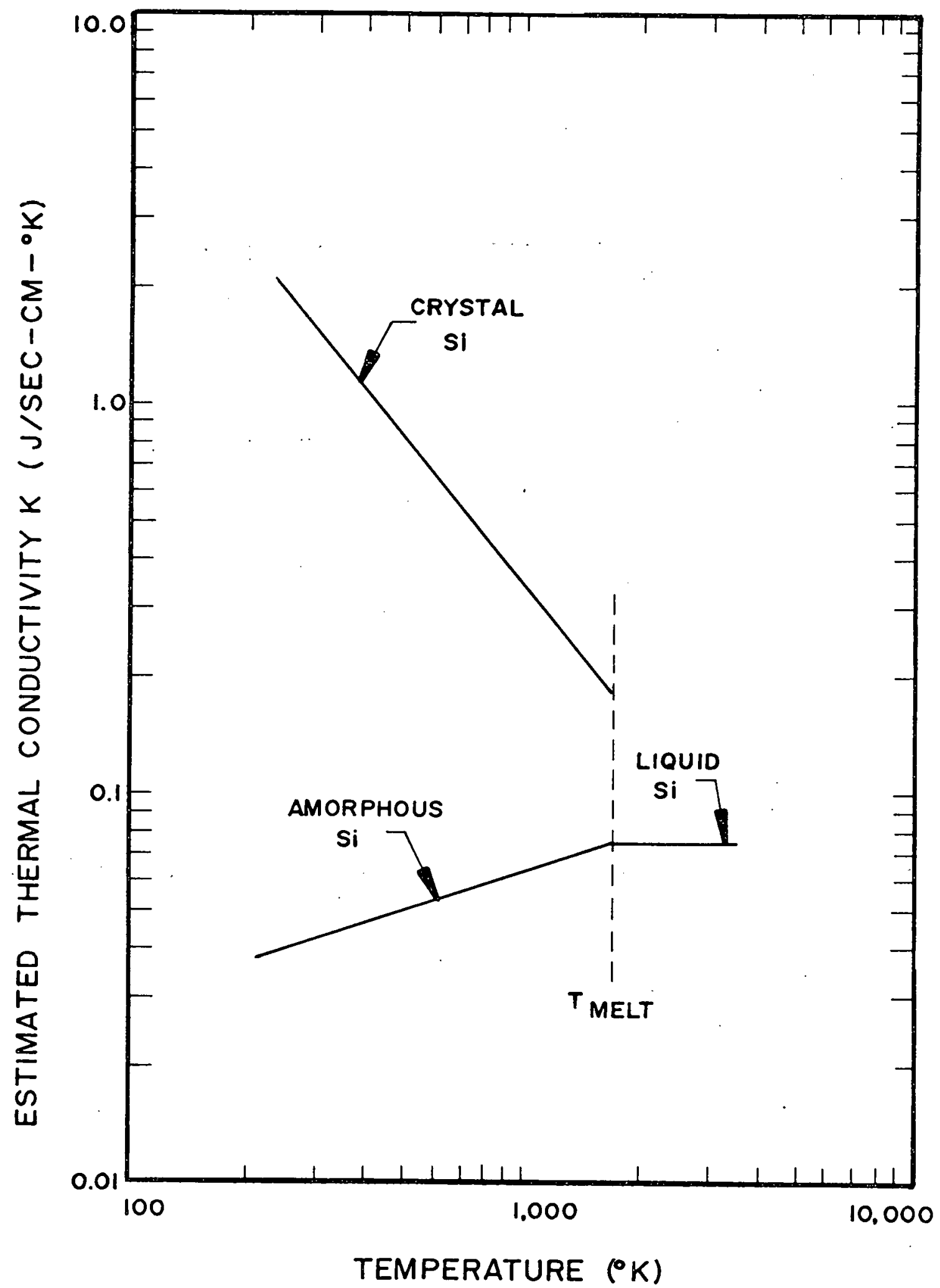

Figure 23. Variation of Thermal Conductivity with Temperature for Amorphous and Crystalline Silicon. 


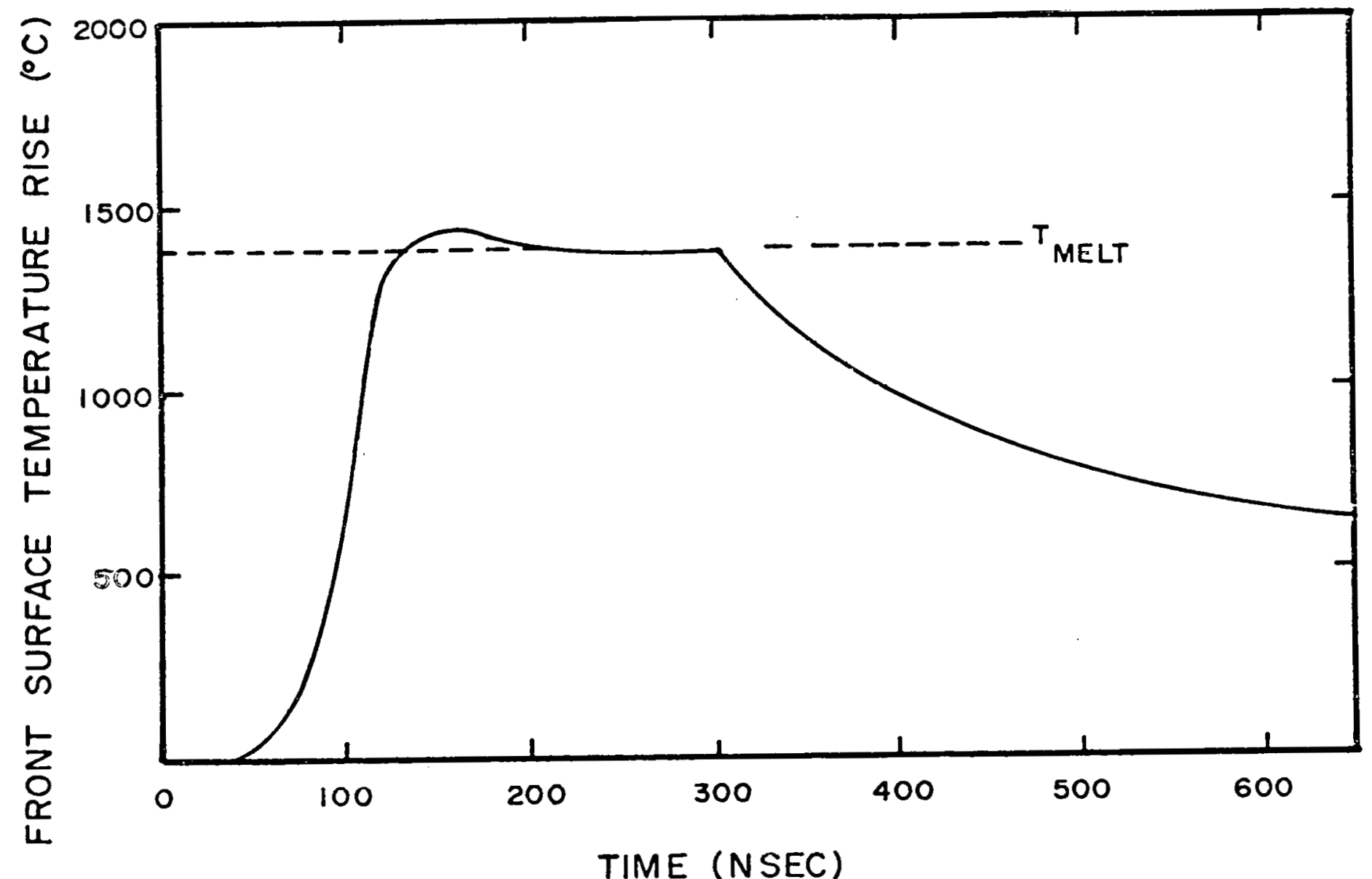

Figure 24. Front Surface Temperature as a Function of Time Following Deposition of Pulsed Electron Deam. 


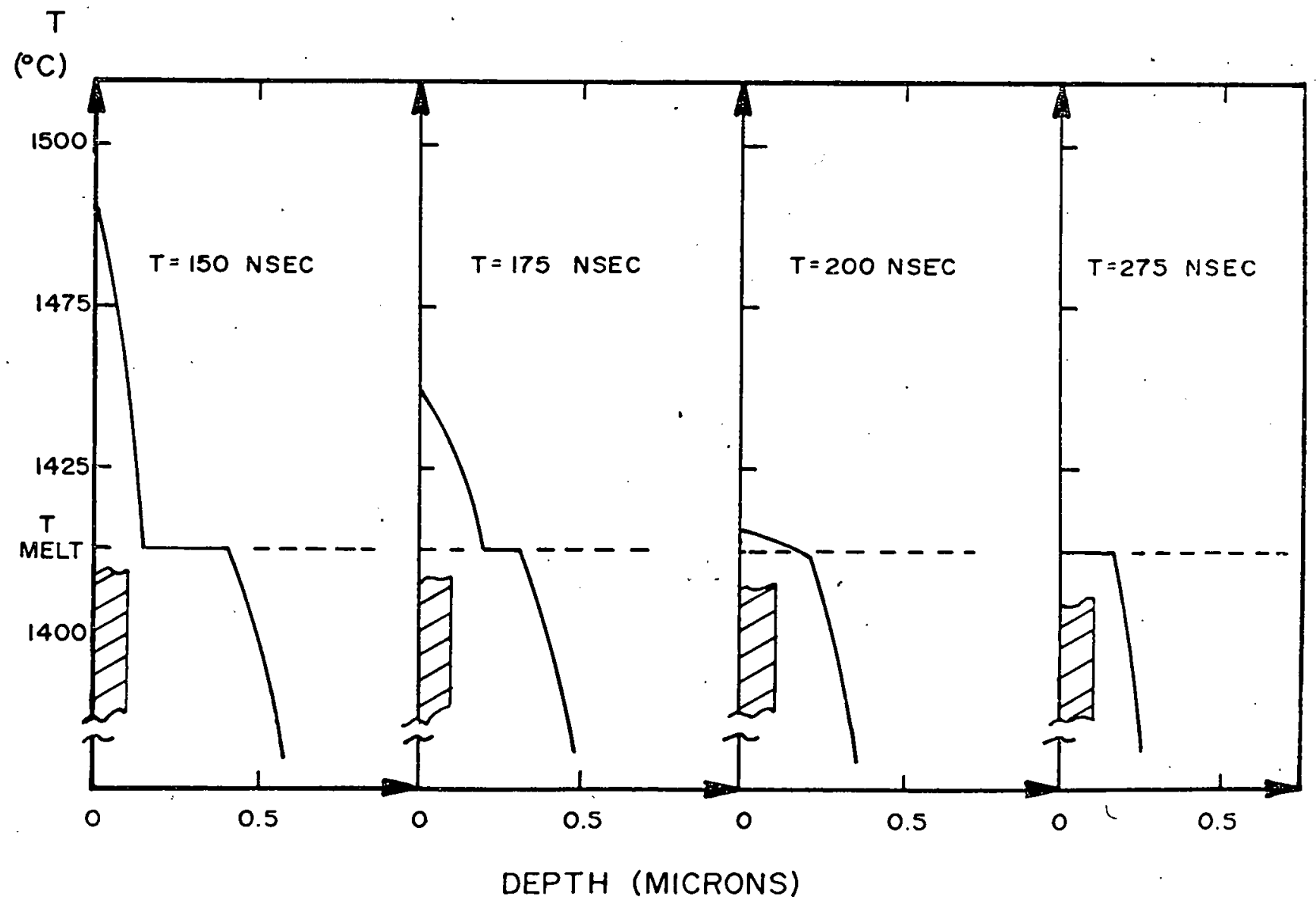

Figure 25. Calculated Temperature Profile During Pulsed Electron Beam Annealing from VXTEMP Output. 


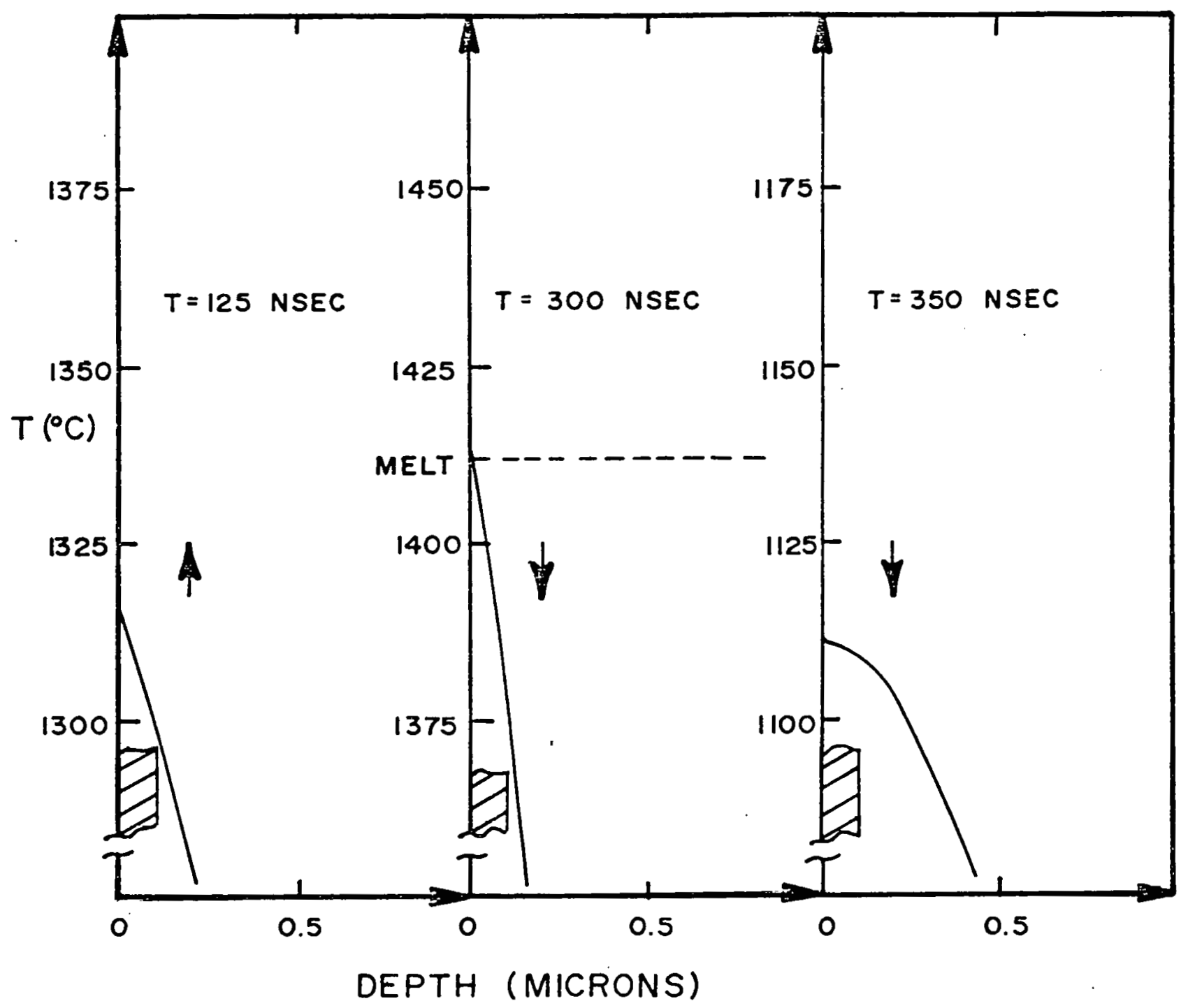

Figure 26. Predicted Temperature Profile After Pulsed Electron Beam Energy Deposition. 
the Young's Modulus, as shown in Table III. Near the front surface the induced thermomechanical stress is

$$
\sigma_{\mathrm{n}} \simeq \frac{\mathrm{E} \alpha \mathrm{T}}{3(1-u)}
$$

where:

$$
\begin{aligned}
& \sigma_{n}=\text { Normal components of stress } \\
& \alpha=\text { Volume expansion coefficient } \\
& E=\text { Young's modulus } \\
& u=\text { Poisson's ratio }
\end{aligned}
$$

The front surface temperature at $\mathrm{x}=0$ was calculated using this analytical technique and compared with a computer solution shown in Figure 24. The two values agreed within $4 \%$. The error could be further reduced using grid spacings of higher accuracy. Note that the changing slope from the material boundary is an agreement with a calculated value equal to $\mathrm{K}_{1} / \mathrm{K}_{2}$.

\subsection{DESIGN OF AN AUTOMATED PRODUCTION PULSE PROCESSOR}

The electron beam pulse generator that has been used to date can serve only to show feasibility and to develop some of the process parameters for annealing ion implantation. For use in an automated production facility and to meet the objectives of the mid-1980's, dedicated pulsed electron beam generators must be developed which must have a higher throughputs and different operational characteristics. Under this. program, Spire is determining the basic functional requirements for a solar cell pulse processor which will operate continuously with throughput compatible with a $100 \mathrm{~mA}$ ion implanter. A conceptual design of a combined implanter-pulse processor is shown in Figure 27.

A set of functional requirements has been defined to represent minimum performance objectives to be necessary for a pulse processor. These functional requirements are summarized in Table IV. The pulse processor must provide continuous, uniform, and reproducible annealing at a rate comparable with a 100 $\mathrm{mA}$ ion implanter. In addition to being synchronous with the ion 


\section{TARLE III}

Summary of Measured Fracture Thresholds for Pulsed

Electron Beam Heating as a Function of Silicon

Crystallographic Orientation

\begin{tabular}{|c|c|c|}
\hline \multirow[t]{2}{*}{ Parameter } & \multicolumn{2}{|c|}{ Crystallographic Orientation } \\
\hline & $(111)$ & $(100)$ \\
\hline $\begin{array}{l}\text { Microfracture of } \\
\text { Unimplanted Wafer }\end{array}$ & $0.22 \pm 0.02\left(\mathrm{cal} / \mathrm{cm}^{2}\right)$ & $0.30 \pm 0.02\left(\mathrm{cal} / \mathrm{cm}^{2}\right)$ \\
\hline $\begin{array}{l}\text { Microfracture of } \\
\text { Junction Implanted Wafer }\end{array}$ & $0.27 \pm 0.03\left(\mathrm{cal} / \mathrm{cm}^{2}\right)$ & $0.30 \pm 0.03\left(\mathrm{cal} / \mathrm{cm}^{2}\right)$ \\
\hline Implant Anneal & $>0.2\left(\mathrm{cal} / \mathrm{cm}^{2}\right)$ & $>0.2\left(\mathrm{cal} / \mathrm{cm}^{2}\right)$ \\
\hline Young's Modulus & $1.9 \times 10^{12}$ dynes $/ \mathrm{cm}^{2}$ & $1.3 \times 10^{12}$ dynes $/ \mathrm{cm}^{2}$ \\
\hline
\end{tabular}

Notes: Si - $\quad 7.6 \mathrm{~cm}$ Diameter, 250-500 $\mu \mathrm{m}$ thick p-thick

$3 \pm 1 \mathrm{ohm} / \mathrm{cm}$

Implant $-10^{15} 31_{\mathrm{p}} \mathrm{cm}^{-2}$ at $10 \mathrm{keV}$ 
TABLE IV

FUNCTIONAL REQUUREMTENTS FOR PROTOTYPE PULSED ELECTRON BEAM PROCESSOR

(Compatible with 100 ma Implanter Throughput.)

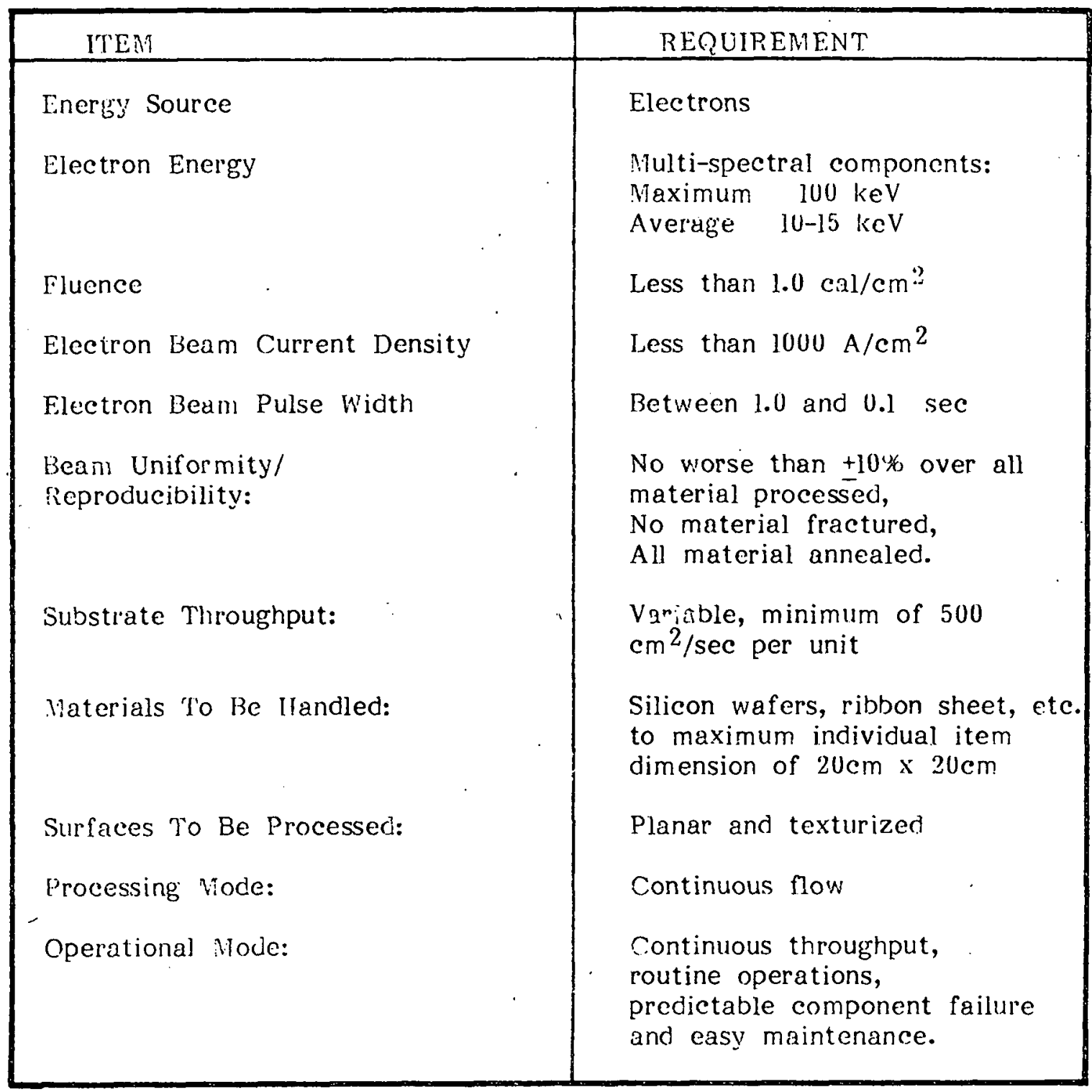




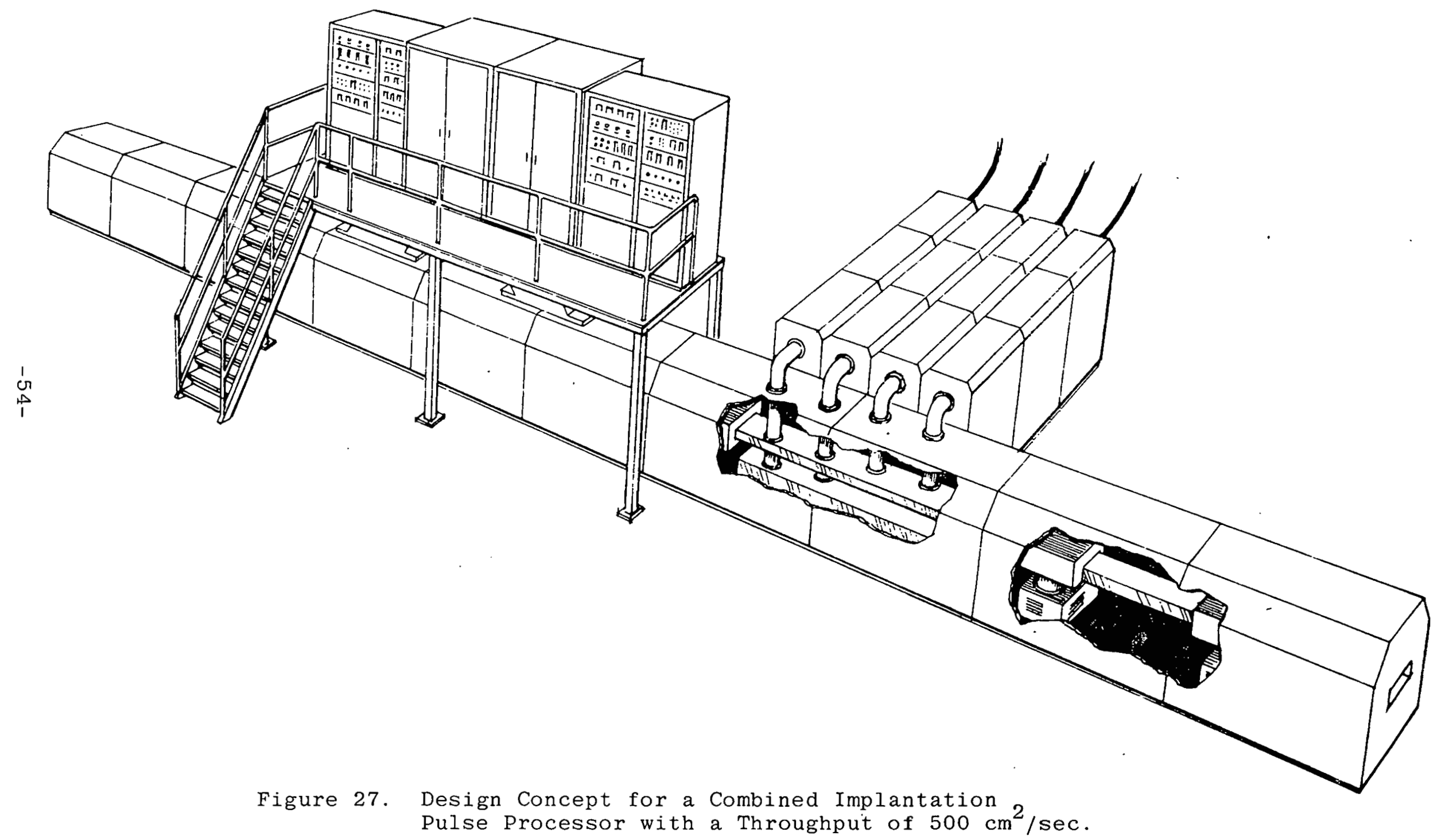


implanter throughput, the design philosophies of a prototype electron beam processor are similar to those of an automated ion implanter. A particularly important aspect is that the prototype pulser has multiple electron beam sources similar to the ion sources of the implanter. Multiple sources allow for system redundancy for reliability, continuous processing, and predictable maintenance. Components of the processor are identified in Figure 28.

Each of the major subsystems within the electron beam processor are shown diagrammtically in Figure 29. Approximately 4 electron sources are required. Functional requirements of the major subsystems are as follows:

Variable High Voltage Power Supply

A variable high voltage power supply will provide basic electrical energy for the pulse electron beam processor. The power supply will be powered by

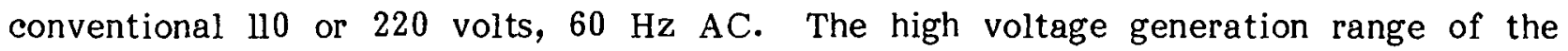
supply will be between 50 and 300 kilovolts. The current which it can supply will be up to 100 milliamperes. Power supply regulation in both current and voltage will be $+2 \%$.

\section{Charging Current Limiter}

Charging of the pulsed electron beam sources pulse forming networks (PFN) will be from the high voltage power supply through a charging current limiter. This limiter is necessary to prevent power supply burnout should shorting occur within the high voltage PFN. The charging current limiter will be a high power resistor of 10,000 ohms, 100 watt continuous power.

\section{Pulse Forming Network (PFN)}

A PFN capable of being charged to a high voltage will be the basic energy store from which the electron beam pulse energy is extracted. This PFN will be a transmission line geometry with an impedance of between 1 and 50 ohms. The voltage to which this transmission line will be charged is between 50 and 300 kilovolts, compatible with the high voltage power supply. 


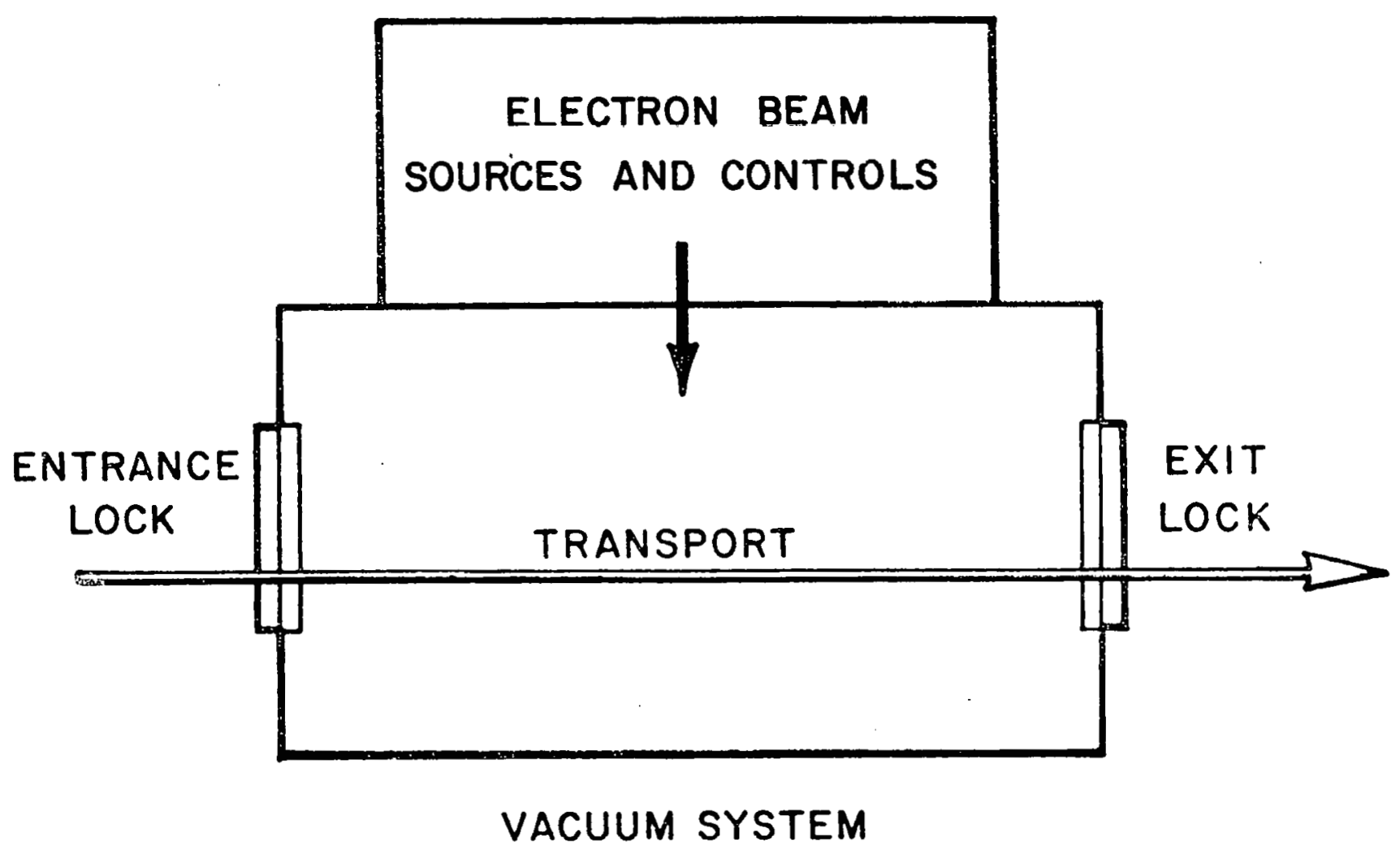

Figure 28. Components of Automated Production Processor. 


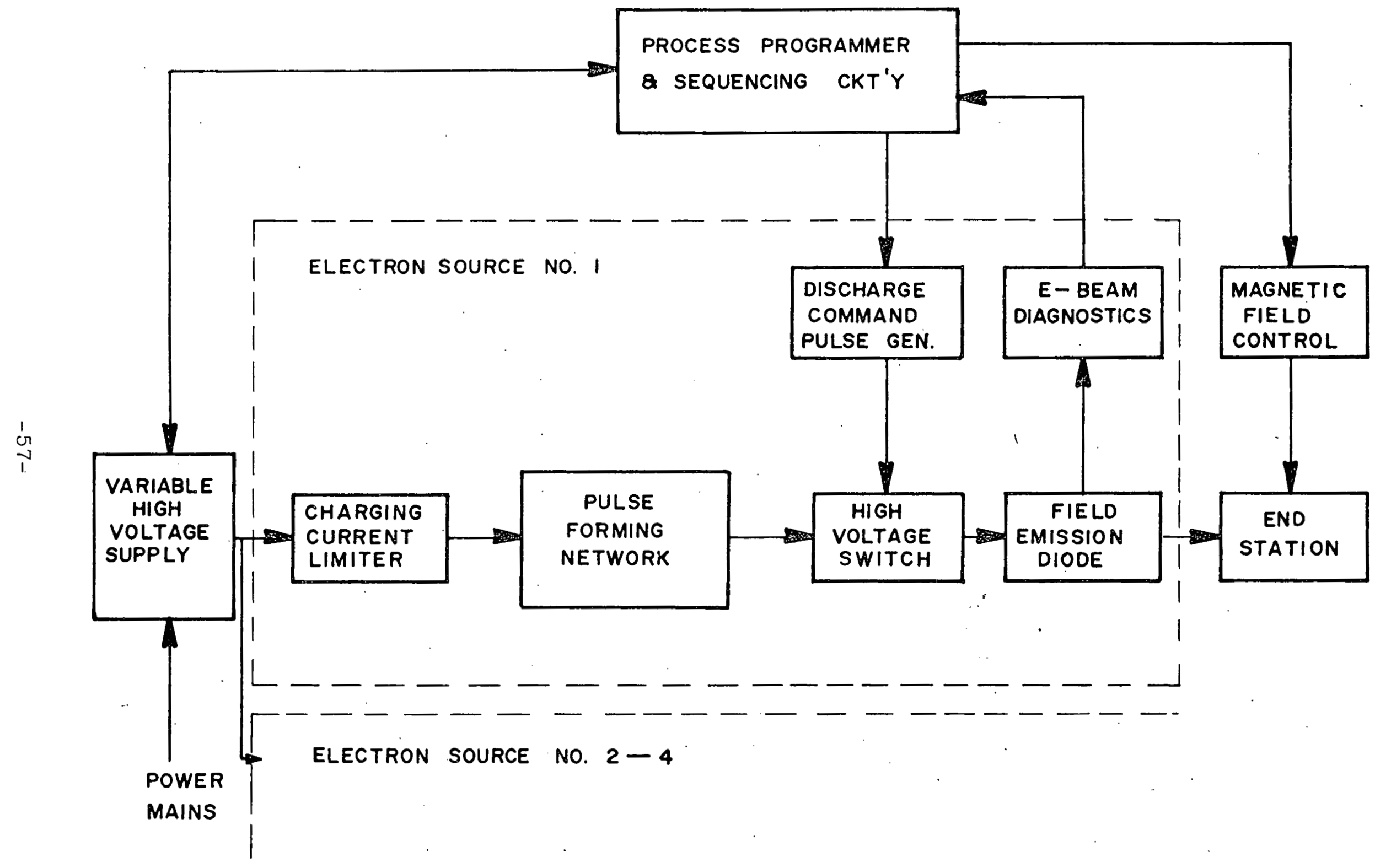

Figure 29. Electron Beam Pórcessor System Elements. 


\section{High Voltage Switch}

A command switch is required for discharge of the PFN once it has been charged by the high voltage power supply. This switch will consist of a trigatron geometry with high voltage spark initiation occurring on the ground side of the system, i.e. the diode. The trigatron switch will be initiated with a high voltage pulse not less than $10 \%$ of the transmission line charging voltage. Switch jitter will be controlled to within \pm 1 microsecond. Circulation of the gas insulation of the switch for cooling and filtering will be provided for firing rates greater than one pulse per second.

\section{$\underline{\text { Field Emission Diode }}$}

PFN energy will be switched via a trigatron to the field emission diode. The field emission diode will consist of a vacuum coax region, a dielectric high voltage insulating structure, a field/plasma emission cathode, and a transmission anode. Associated with the diode will be fast, high voltage diagnostics consisting of a return current shunt and a capacitive voltage monitor, both built into the vacuum coax wall. These diagnostics will be calibrated for performance at the levels of processing.

\section{End Station}

The end station subsystem will be compatible with that of the $100 \mathrm{~mA}$ automated production ion implanter, that is, vacuum interlocks and silicon transport will be identical to that used by the ion implanter. An additional requirement, however, is the presence of a 1-10 kilogauss magnetic field normal to the surface of the silicon to be processed. This will be provided for each of the electron sources by an electromagnet. Vacuum requirements for the electron beam processor will be compatible with that of the ion implanter. When final integration processor and implanter are accomplished, a common vacuum and silicon transport system will be used.

\section{Process Programmer and Sequencer Controls}

In order to monitor and control the electron beam processor parameters and timing sequences, a microprocessor control console will be used. Eventually this 
will be linked with that of the $100 \mathrm{~mA}$, automated production ion implanter. The processor will initiate a discharge upon command, via an intermediate voltage pulse generator which breaks down the trigatron switch in the high voltage system. The control console will also record the response of the diagnostics for the field emission diode such that beam parameters are precisely monitored on 'a pulse-to-pulse basis. The magnetic field parameters in the transport system will also be programmable.

The electron beam source will become a basic building block: in the automated processing line to be developed to achieve 1986 and greater production goals. The processor described will satisfy the requirements of, an ion implanter with 100 milliamperes of current and a throughput of $500 \mathrm{~cm}^{2} / \mathrm{sec}$ for junction implants. Individual electron beams, similar to the case of ion sources, will be provided by transmission line pulse forming networks. This approach offers advantages similar to those of the multi-source ion implanter. Electron beam source redundancy and off line start-up are achieved. Reliability of moderate level individual sources is improved, and the entire system reliability, reproducibility and duty cycle is thereby enhanced. 


\section{THIS PAGE}

\section{WAS INTENTIONALLY \\ LEFT BLANK}




\section{SECTION V}

\section{SUMMARY}

This report has described the third quarter results of a program whose purpose is to develop ion implantation and associated processing for long range automated production of solar cells. Significant accomplishments during this reporting period include:

(i) A dedicated, state-of-the-art solar cell implanter has been operational for six months. Manufacturing and quality control procedures have been defined for implant uniformities better than $+10 \%$. Throughputs of 300 wafers per hour have been achieved. Cells processed using these implant specifications have efficiencies of $15 \%$ AMI.

(ii) The design specifications for a $100 \mathrm{MW} /$ /year automated production ion implantation have been completed. This implanter will deliver 100 $\mathrm{mA}$ of mass separated ion beam onto silicon wafer, sheet, or ribbon material-transported through the machine in carriers. Analysis, using JPL-SAMICS methods, shows that the cost for solar cell junction implants will be only $\$ 0.01$ per peak watt if $100 \mathrm{~mA}$ facilities are available.

(iii) High-efficiency back surface fields by ion implantation of boron in an $\mathrm{n}^{+} \mathrm{pp}^{+}$structure with cell efficiencies of $13.8 \%$ AMO have been demonstrated. Feasibility of effective annealing BSF implants by pulsed electron beams has also been shown.

(iv) The functional requirements for a pulse processor which is compatible with the throughput and operational modes of a $100 \mathrm{~mA}$ ion implanter have been defined. 
THIS PAGE

\section{WAS INTENTIONALLY LEFT BLANK}




\section{SECTION VI}

NEW TECHNOLOGY

No new technology has been developed to completion during this quarter. 
THIS PAGE

\section{WAS INTENTIONALLY LEFT BLANK}




\section{REFERENCES}

1. ERDA/JPL Contract 954289, Spire Corporation, 1976.

2. ERDA/JPL Contract 954363, Motorola Inc., 1977.

3. ERDA/JPL Contract 954405, Texas Instruments, Inc., 1977.

4. ERDA/JPL Contract 954352, RCA, 1977.

5. Csepregi, L., W. K. Chu, H. Muller, J.W. Mayer, and T.W. Sigmon, Radiation Effects, 28,227 (1976).

6. Csepregi, L., J.W. Mayer, and T.W. Sigmon, Appl. Phys. Lett., 29, 92, (1976). 